\title{
El debate académico sobre los exámenes para las distintas profesiones de la Arquitectura (1781-1783)
}

(El arquitecto según JUAN DE VILLANUEVA)

\author{
José Enrique García Melero *
}

Hay que situar los orígenes de la creación de la junta de Comisión de Arquitectura el 22 de marzo de 1786 en la teoría artística y en la actitud política de la Academia durante el período comprendido entre los años 1768 y 1777. En esa década este centro de las Bellas Artes envió al rey a través de su protector, el primer Secretario de Estado, una serie de interesantes representaciones redactadas por sus consiliarios en las juntas particulares en estrecha relación con el pensamiento de los profesores, a quienes se solía solicitar que escribieran informes para que les asesoraran en el campo de la arquitectura. En ellas se indicaba la necesidad urgente de ejercer un control efectivo desde este organismo de las obras, que entonces se realizaban en España a fin de depurarlas del gusto barroco y establecer un nuevo clasicismo, el lenguaje artístico internacional representativo de la nueva época de la llustración.

Para lograr este objetivo era totalmente necesario acabar con los gremios, anclados en el uso de una tendencia artística ya trasnochada, y que, sin embargo, seguían dominando en una gran parte la práctica del arte del país. De nada había valido que en el artículo XXXIII de los estatutos de la Academia de 1757 se prohibieran las juntas, congregaciones o cofradías establecidas, o que se intentasen constituir después en la Corte para reglar los estudios y las prácticas de las nobles artes. Se censuraba de una forma especial la de Nuestra Señora de Belén, domiciliada en la parroquia de San Esteban de Madrid. Todos estos centros de origen religioso se podrían dedicar en adelante a los ejercicios de

* Dpto. $H^{a}$ del Arte. UNED. 
piedad y devoción, para los que estaban aprobados. Pero no se les permitía usurpar los títulos de Colegios de Arquitectos, Academia de Arquitectura, ni otros semejantes, ni dedicarse a tasar, ni medir, ni dirigir fábricas, sin tener los títulos expresados o presentarse al examen de la Academia para conseguirlos. Se establecían, así, penas de multa de cien ducados por la primera vez, doscientos por la segunda y trescientos por la tercera'.

Las dos representaciones del 4 y 20 diciembre de 1768 , por las que se pedía que no se pudieran construir retablos o altares de madera u otra materia, fuentes, portadas de edificios públicos o casas de particulares de consideración, sin que primero se presentaran los diseños a la Academia ${ }^{2}$, son los precedentes más remotos de la famosa "Consulta al Rey sobre la arquitectura de los Templos", redactada en la junta particular de consiliarios del 10 de agosto de $1777^{3}$. Aquellas peticiones fueron en parte frenadas por los dictámenes del fiscal conde de Campomanes del 10 de enero y 1 de marzo de $1769^{4}$. En ellos, aún coincidiendo con la Academia en esta necesidad, se establecía un complejo proceso burocrático para la presentación de los proyectos, que debían pasar primero y por último a través del Consejo de Castilla. Aunque la Academia debía ser la encargada de juzgar los diseños supervisados por un artista nombrado para ello, perdía con tal ejercicio administrativo su casi total autonomía, pues tan solo dependía del rey a través de su protector, el secretario de Estado,

Estatutos de la Real Academia de San Fernando de Madrid. En Madrid, en Casa de D. Gabriel Ramírez, impresor de la Real Academia, año MDCCLVII (1757). El artículo XXXIII en págs. $89-90$.

2 La copia de la representación del 4 de diciembre de 1768 de los consiliarios de la Real Academia de Bellas Artes de San Fernando se halla en AASF: Leg. 28-1/2. El original se localiza en AHN, Consejos, Leg. 2076, núm. 5. Este documento fue publicado por CARRETE PARRONDO, Juan, en "Pedro Rodriguez de Campomanes. Informes sobre la Real Academia de Bellas Artes de San Fernando", en la Revista de Ideas Estéticas, 1977, núm. 137, págs. 75-90. Joaquín Bérchez se refiere a él y halla precedentes valencianos en su libro. Arquitectura y Academicismo. Valencia, Edicions Alfons el Magnànim, Instituciò Valenciana d'Estudis i Investigació, 1987, págs. 199 y ss.

3 Representación al Rey de los consiliarios de la Academia de San Fernando. Actas de la junta particular del 10 de agosto de 1777 . AASF: $3 / 123$, fol. 77 y ss. La consulta está fechada en Madrid el 14 de agosto de 1777 y remitida entonces.

4 Los informes de Pedro Rodríguez de Campomanes, fiscal del Consejo de Castilla, del 10 de enero y 1 de marzo de 1769 se hallan en el AHN, Consejos, leg. 2076, núm. 7 y fueron publicados por CARRETE, Juan, en op. cit. Una copia sin firma del primer dictamen se localiza en la Academia, aunque está datada el 23 de febrero de 1770: AASF: Leg.: 28-1/2. Esta última está encabezada por el Conde de Aranda como presidente, D. Miguel M ${ }^{a}$ de Nava, D. Andrés Maraver, D. Pedro León, el Marqués de San Juan de Tasó, Francisco Losella y Pedro de Ávila. Ya me referí a este documento en mi artículo titulado "Arquitectura y burocracia: el proceso del proyecto en la Comisión de Arquitectura de la Academia (1786-1808)", en Espacio, tiempo y forma, núm. 4. Madrid, Facultad de Geografía e Historia de la UNED, 1991, págs. 283-348. 
quedándose en función de tal respuesta fiscal en parte subordinada a ese organismo político.

Las reales órdenes circulares del 23 y 25 de noviembre de 1777, - precisamente el mismo año durante el cual el conde de Floridablanca accedió al cargo de protector de la Academia- que disponían que todos los proyectos de obras públicas se enviaran desde entonces a ese centro de las Bellas Artes para su examen, aprobación, denegación o corrección, realizaron los deseos académicos de 1768 en una gran parte ${ }^{5}$. Sin embargo, el Consejo siguió entrometiéndose de continuo en la labor de este centro, lo cual produjo cierto malestar.

El origen inmediato de tales circulares se halla a mi juicio, no obstante, en los pleitos mantenidos por la Real Academia de San Carlos de Valencia contra el Gremio de Carpinteros de esta ciudad durante este mismo año de 1777, que comprometió a la de San Fernando por su condición de institución-madre. Este problema fue el tema principal de debate en toda una larga reunión de la junta particular del 25 de junio, cuyas actas reflejan con gran minucia y extensión el asunto ${ }^{6}$. Ese Gremio había denunciado a los académicos José Puchol, José Esteve y Pedro Juan Guisnut por no pagarle las contribuciones, que les tocaba, como a los demás maestros, y en contra de sus privilegios académicos, que les desvinculaban de este organismo al prohibir los estatutos a los miembros de la Academia el pertenecer a esa asociación ?

Así, entre los años de 1777 y 1786 se abrió una nueva y segunda fase en los orígenes de la junta de Comisión de Arquitectura, que culminó con su fundación. Este período estuvo delimitado por las luchas existentes entre el Consejo de Castilla, que no se resignaba a dejar de intervenir de

La carta circular a los Arzobispos, Obispos y demás Prelados Eclesiásticos fue leída en la junta particular de la Academia de San Fernando del 29 de noviembre de 1777, convocada exclusivamente para dar cuenta de esta resolución real. AASF: $3 / 123$, fol. 98 anv. y ss. Se envió a la Academia junto con un oficio del Conde de Floridablanca como Protector de la Academia del 23 de noviembre de 1777. En el legajo 1/19-29 se halla duplicada la circular del 29 de noviembre de 1777 firmada por el Conde de Floridablanca.

- Actas de la junta particular del 25 de junio de 1777 de la Real Academia de Bellas Artes de San Fernando, AASF: 3/123, fols. 55 anv. -73 rev. El pleito entre la Cofradía de Carpinteros de Valencia y la Real Academia de Bellas Artes de San Carlos ya había sido tratado en las juntas del 5 de mayo (fol. 51 rev.) y del 1 de junio (fol. 53 rev. -54 anv.). Sin embargo, toda la historia del proceso se halla en las actas de la del 25 de junio arriba indicada.

7 Este problema y la real resolución del 22 de junio de 1777 ha sido tratado por BEACHEZ, Joaquín, en su magnífica tesis doctoral, Arquitectura y Academicismo. Valencia, Edicions Alfons el Magnànim, Institució Valenciana d'Estudis i Investigació, 1967. Véase el capítulo 11, el epigrafe titulado "La Real Resolución de 22 de junio de 1777» y su “siniestra interpretación». Su estudio se basa en la documentación de la Academia valenciana. 
alguna forma en ese control, y la Academia, deseosa de conservar plenamente su autonomía concedida por el rey. Pero, además, entonces se establecieron una serie de medidas complementarias, que trataban de ejercer un mayor rigor en los exámenes para la creación de académicos de mérito, aspecto objeto de estudio en este artículo. La Academia debía cuidar su imagen. Para lograrlo era preciso conceder tales títulos tan solo a artistas realmente cualificados para el ejercicio de la profesión en el uso del lenguaje clásico. Si no se actuaba de esta forma, se podría establecer un parangón entre su actuación y la de los gremios.

El 17 de octubre de 1779 el conde de Floridablanca, bajo la inspiración de Antonio Ponz, haciéndose partícipe de los serios reparos académicos de 1769 a los dictámenes fiscales de Campomanes ${ }^{8}$, remitió al Consejo una real orden, que finalmente alejaba de una forma oficial a este organismo del control administrativo de los proyectos arquitectónicos ${ }^{9}$. A partir de entonces tales diseños no debian ser admitidos por el Consejo, aunque se costearan de los bienes propios de los pueblos, sin haber pasado antes la censura de la Academia. Se invertían de esta forma los términos del problema y se acababa de algún modo, aunque no del todo, con una burocracia excesiva, ideada en gran medida por Campomanes, que quitaba efectividad a este instituto de las Bellas Artes, sumergiéndolo en largos procesos administrativos, que rentilizaban la resolución de los dictámenes. La Academia quería ser la única institución gestora de este proceso, ya de por sí bastante complicado. Sin embargo, en el verano de 1783 todavía los escribanos de Cámara remitían proyectos para la censura académica, lo cual obligó a este centro a recordar al Consejo esa real resolución de $1779^{10}$.

La fundación de la Junta de Comisión de Arquitectura por la real orden del 22 de marzo de 1786, estuvo precedida por otra del día 10 de ese

8 Carta firmada por un Abate dirigida a Iriarte sobre las respuestas fiscales del 23 de febrero de 1770 a lo que representó la Academia el 4 y 23 de diciembre de 1768. (S. I.: Madrid, S. f.: febrero de 1770). AASF: Leg.: 28-1/2.

- Las quejas en la junta particular sobre la interferencia del Consejo de Castilla en esta labor de la Academia ya se hallan presentes en las Actas de la junta particular del 11 de julio de 1779. AASF: $3 / 123$, fol. 152 anv.-153 rev. Este mismo tema se trató en la junta particular del 8 de Agosto de 1779. En tal sentido se halla la representación de la Academia del 12 de agosto de 1779. Copia en el AASF: Leg. 28-1/2. No obstante, los problemas administrativos entre el Consejo y este centro siguieron ya en 1783. Así se manifiesta en las actas de la junta particular del 6 de julio de ese año, AASF: 3/123, fol, 260 anv.-262 anv. En estas actas se cita literalmente la real resolución del 17 de octubre de 1779 enviada al Consejo por vía reservada, de un gran interés para conocer las relaciones complejas entre ambos organismos.

10 Actas de la junta particular del 6 de julio de 1783 de la Real Academia de Bellas Artes de San Fernando. AASF: 3/123, fol. 260 anv.-262 anv. Las actas están firmadas por Isidro de Granja. 
mismo mes, en la que se mandaba a la Academia arreglar su plan de estudio de Arquitectura, después de ser consultados los profesores de este arte ${ }^{11}$. Es de señalar, asi pues, como tal creación se acompañó de una serie de medidas complejas, muy racionalistas y borbónicas, de diversos tipos, y complementarias entre sí a lo largo de varios años, entre 1777 y 1786. También es posible concluir aquí que uno de los motivos de la organización de la Junta se halla con cierta seguridad en los problemas de competencias, políticas y administrativas, existentes entre la Academia y el Consejo a la hora de recibir y despachar finalmente los proyectos de obras públicas llegados para ser censurados. No obstante, la causa inmediata se atribuyó en la misma real cédula fundacional a un problema esencialmente burocrático: la ingente cantidad de expedientes que Antonio Ponz, el secretario de la Academia, debía atender por sí solo y sus repetidas quejas por el tiempo empleado en esa labor, lo cual le impedía redactar su famoso "Viage de España". De esa forma se creaba un servicio administrativo propio, receptor y censor de tales proyectos.

Esta era, en resumen, la situación de la Academia en los años inmediatamente anteriores al interesante debate sobre la recepción de académicos de arquitectura acaecido entre 1781 y 1783, previo a la creación de la Junta de la Comisión de Arquitectura. Hay que ver, por lo tanto, este discurso de los profesores de ese arte sobre los exámenes de los arquitectos y las distintas profesiones de la Arquitectura como un aspecto importante en los años inmediatamente anteriores a esa fundación. Se sitúa, así pues, dentro del complejo entramado de medidas, que entonces se tomaron para resolver distintos problemas relacionados con esa disciplina artística.

\section{EL DEBATE SOBRE LOS EXÁMENES DE LOS PROFESIONALES DE LA ARQUITECTURA EN LA ACADEMIA (1781-1783)}

Entre 1781 y 1783 la Real Academia de Bellas Artes de San Fernando se ocupó de mejorar el método para la creación de académicos de arquitectura. Pero también se vieron inmiscuidos en el mismo proceso otros profesionales de este género artístico, como eran los maestros de obras,

Estas importantes reales resoluciones del 10 y 22 de marzo de 1786, por las cuales se pedía un plan de estudios de la arquitectura y se creaba la Junta de Comisión de Arquitectura, fueron leídas en la junta ordinaria del 2 de abril de 1786, recogiéndose literalmente el texto en ellas. AASF: $3 / 85$, fol. 7 anv.-10 anv. El original de la del 10 de marzo se halla en AASF: Leg. $1-18 / 9$. 


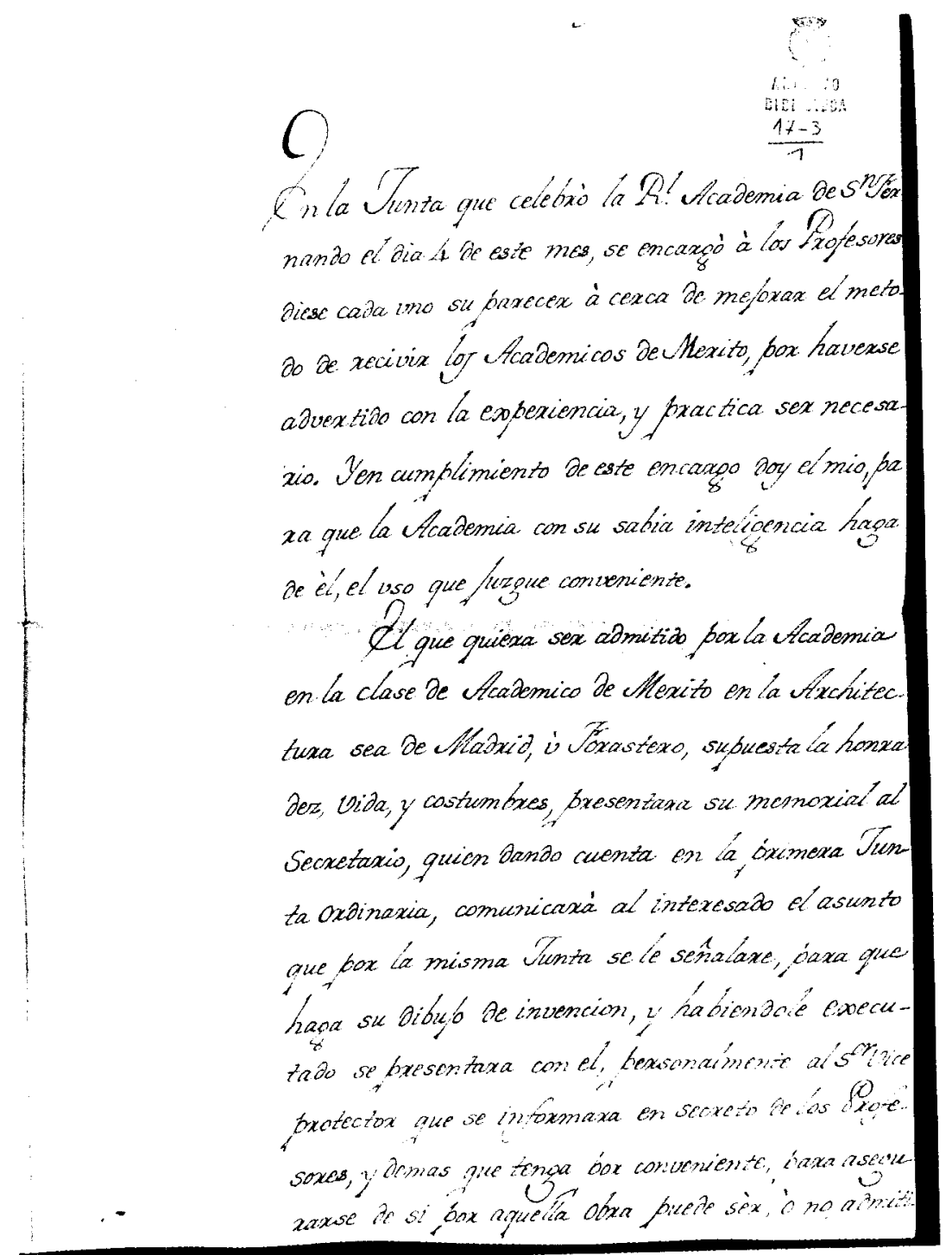

Fig. 1. "Parecer de Ventura Rodríguez acerca de mejorar el método de recibir los académicos de mérito." Madrid, 31 de marzo de 1781. A.A.S.F.: 17-3/1, fol. 1 anv.2 anv. 


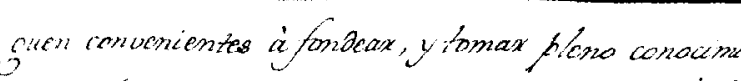
enti Der cluxiro Det óxetendiente, en que se empieaxà

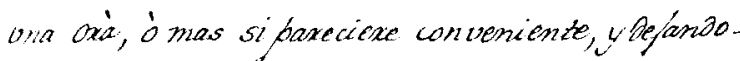
paxa obo dia la continuacion del examen se pxosequixa' fox espario ar bor oxas vitites bxoponiendo, del mismo modo que se emperio á antecedente, Las qües tiones teoxicas, y pxacticas que sean bastantes ba xa tomax mas áfordo é bieno conocimiento que es necesaxio a gxaduax el clexito, tenienas siompxe a la oista Loo Dibu, os, solucunes, pxactica; y exo bexien cia notoxia.

Con este conociniento se razá in untacion solamenze box lool (Yofesoxes Axcritectos convocador al examen en que tendxa woxio tamóien el Pixectox

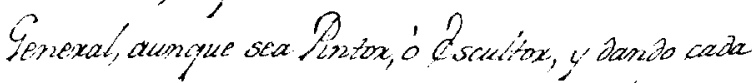

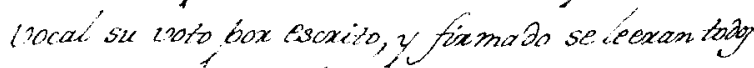
fox el Secketaxio, y ia biuxalidad becidixa ef cllexi

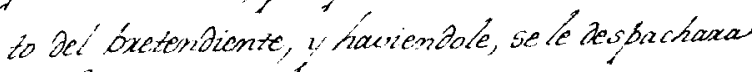

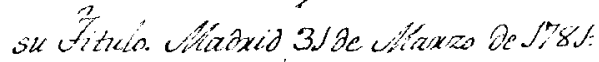

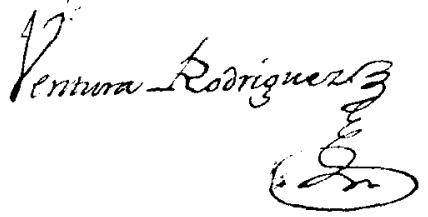

Fig. 2. "Parecer de Ventura Rodríguez acerca de mejorar el método de recibir los académicos de mérito." Madrid, 31 de marzo de 1781. A.A.S.F.: 17-3/1, fol. 1 anv.- 
los albañiles, los canteros y los carpinteros. Lo dispuesto en el artículo XXXIII de sus estatutos no daba según los profesores de este centro una garantía y una fiabilidad totales del mérito verdadero de los pretendientes a este título ${ }^{12}$. Los aspirantes tan sólo debían presentar a la Academia los dibujos de planes y elevaciones, sin que se tuviera una seguridad absoluta de haber sido inventados por ellos y de su propia mano, pues podrían haberse valido de otros profesores para ejecutarlos mejor. Este centro deseaba ahora acabar con ciertos abusos, que habían permitido conceder tal honor, y con él la facultad de construir todo tipo de edificios, a personas de cuya capacidad en el ejercicio de esta profesión el centro no tenía plena seguridad, arriesgándose a remunerar a sujetos faltos de verdadero mérito ${ }^{13}$.

Se había llegado a pensar en la revisión de ese artículo al recibirse las solicitudes de algunos pretendientes, empeñados en que se les hiciera académicos poco tiempo antes del concurso general de premios del año 1781. No querian presentarse a las oposiciones, en donde podrian haber demostrado claramente su habilidad. Sin embargo, deseaban ser jueces de otros discipulos, que tal vez supieran más que ellos.

Este asunto tan problemático fue estudiado con detenimiento en la junta ordinaria del 4 de marzo de 1781 . Se acordó entonces en ella, que los profesores directores y tenientes directores de arquitectura, así como también José Moreno, asistente continuo a todas estas reuniones, expusieran sus pareceres por escrito sobre los requisitos, que se deberían exigir para lograr la recepción más adecuada de los académicos arquitectos, tal y como después harian en el transcurso de esa primavera.

Antonio Ponz envió el 16 de marzo un oficio al protector, notificándole lo acordado sobre el particular en la junta. Le indicaba la intención de la

12 El artículo XXXIII sobre la recepción de académicos de los Estatutos del 19 de marzo de 1755 dice lo siguiente: "La Junta Pública, la General, y la Ordinaria, tendrán facultad de recibir en la clase de Académicos de Honor, a todas las personas de carácter distinguido que proponga el Protector, o Viceprotector sin necesidad de que preceda Memorial, o súplica de parte del propuesto. Pero el que solicitare ser admitido en la clase de Académico de Mérito, ya resida en esta Corte, o ya fuera de ella deberá presentar Memorial al Protector, o Viceprotector, y siendo Pintor un Cuadro de su mano, siendo Escultor una Estatua, Busto o Bajorrelieve, y siendo arquitecto el Plano y elevaciones de un Edificio para que reconocidos y examinados en cualquiera de las tres Juntas se forme juicio de su mérito; después de lo cual se votará secretamente para su admisión. Y en el caso de que el pretendiente no haya sido matriculado, discípulo de la Academia: necesitará para ser admitido tener a su favor dos de las tres partes de votos que estuvieren presentes; pero, si el pretendiente fuere de los Discípulos de la Academia, le bastará la pluralidad de votos para quedar admitidon (...).

13 Archivo de la Real Academia de Bellas Artes de San Fernando, a partir de ahora AASF, leg. 1/17-3. Borrador de un oficio de Antonio Ponz enviado al protector Conde de Floridablanca. Madrid, 15 de enero de 1783 
Academia de exponer todas estas razones al rey de una forma meditada. Se había decidido que, mientras que se llegara a una determinación del agrado real y aprobada por el propio Carlos III, no se otorgaría el grado de académico de arquitectura.

El Conde de Floridablanca contestó al oficio del secretario de este centro con cierto retraso, el 29 de Agosto, desde San Ildefonso. Se dio por enterado de lo dispuesto por la Academia y aprobaba en nombre del rey tal resolución, así como lo acordado en el caso particular presentado entonces de denegar el título de académico de mérito de arquitectura a Manuel Cisneros, en tanto no se resolviera alguna norma sobre el particular.

Los informes de los profesores de arquitectura fueron llegando a lo largo de la primavera de 1781 a la Secretaría de la Academia. Después, las representaciones de Ventura Rodríguez, Miguel Fernández, José Moreno, Juan de Villanueva, y Pedro Arnal serían extractadas en un escrito por Antonio Ponz ${ }^{14}$. El debate quedó entonces paralizado durante varios meses. Con posterioridad, con fecha ya del 2 de noviembre de 1782, el consiliario Pedro de Silva dio, por último, su criterio personal, pero basado en la lectura previa de los pareceres de los arquitectos. Todas estas opiniones, que coincidian en la necesidad urgente de reforma y en las líneas más generales de las medidas a tomar, originarían la importante Real Orden del 24 de noviembre de 1783, en donde se indicaban las normas oportunas para la recepción de académicos de mérito en la arquitectura y graduación de maestros de obras ${ }^{15}$.

El interés máximo de este debate se centra precisamente en los criterios dados por los principales arquitectos españoles de la época, como Ventura Rodríguez, Juan de Villanueva y Pedro Arnal, que no han dejado escritos manifestaciones importantes sobre su pensamiento teórico; pero que aquí se mostraron preocupados por la forma más adecuada de acceder al ejercicio de su profesión. A ellos hay que añadir las del director Miguel Fernández, del matemático y también arquitecto José Moreno y del consiliario Pedro de Silva, autor de varios discursos y escritos muy significativos sobre el estudio de la arquitectura y de las matemáticas en este centro.

Los dos documentos tan expresivos del año 1781, un manuscrito original y un extracto de otro no localizado, redactados por el diseñador y

14 Extracto de pareceres. (S. I.: Madrid, s.f.: 1781). AASF: 1/17-3.

15 Real Orden firmada por el Conde de Floridablanca, dirigida a Antonio Ponz. San Lorenzo, 24 de noviembre de 1783. AASF; leg. 1/17-3. 
constructor del edificio para Gabinete de Ciencias Naturales son, asi pues, unos precedentes importantes por su interés del crucial informe, redactado con motivo de la revisión del plan de estudio de la Academia, de 1792, que recientemente he estudiado ${ }^{16}$. En él se resume todo su pensamiento académico, desconocido hasta hace poco tiempo.

Pero, además, el debate académico y su proceso algo largo, pues mantuvo ocupado a este centro de las Bellas Artes entre 1781 y 1783 , de realización en medidas concretas son bien significativos para delimitar con alguna mayor exactitud una serie de preocupaciones y de disposiciones legislativas posteriores de la Academia. Entre ellas se hallan las encaminadas a regular y proteger la profesión de arquitecto. Fueron dictadas como parte integrante de un auténtico programa político muy ilustrado, diseñado a lo largo de varias etapas para controlar la práctica arquitectónica española dentro del sistema clásico y siempre desde la Academia. Tales juicios de los profesores de arquitectura de 1781 son, así, tan sólo posteriores en cuatro años a las decisiones dictadas en 1777 con motivo de la consulta al rey sobre la arquitectura de los templos. Pero también resultan anteriores en un espacio de tiempo similar a la Real Orden del 22 de marzo de 1786, que creaba la junta de Comisión de Arquitectura, organismo siempre imprescindible para conocer la teoría y la práctica arquitectónica del reinado de Carlos IV ${ }^{17}$.

Estas opiniones también certifican la preocupación profunda existente durante el último cuarto del siglo XVIII para lograr el control de las distintas profesiones de la arquitectura desde la Academia, y, sobre todo, la del académico arquitecto, como uno de los requisitos necesarios para imponer el clasicismo en España. Se inició entonces un debate tan profundo como a veces crítico sobre tal asunto profesional, que, partiendo de la década anterior, de esos años de 1781 a 1783 , hallará su momento más intenso y hasta conflictivo entre 1792 y 1793. En estos años tuvo lugar la polémica entablada entre el matemático Antonio de Varas y los profesores de este arte sobre el estudio de las Matemática en la Academia, la censura de Juan de Villanueva a la Comisión de Arquitectura y a sus

16 Garcia Melero, José Enrique, "Juan de Villanueva y los nuevos planes de estudio", en Renovación, crisis, continuismo. La Real Academia de San Fernando en 1792. Madrid, Real Academia de Bellas Artes de San Fernando, 1992, págs. 12-55.

17 Real Cédula, fechada en el Pardo el 22 de marzo de 1786. Se recogió íntegramente en las actas de la junta ordinaria del 2 de abril de 1786. AASF: 3/85. Sobre la Comisión de Arquitectura de la Academia: Garcia MELERo, José Enrique, "Arquitectura y burocracia: el proceso del proyecto en la Comisión de Arquitectura de la Academia (1786-1808)", en Espacio, tiempo y forma, serie VII, núm. 4. Madrid, Revista de la Facultad de Geografia e Historia de la UNED, 1991, págs. 283-348, con il. 
compañeros en el informe de 1792, y la muy elocuente del viceprotector Bernardo de Iriarte por la importancia, que estos profesionales estaban adquiriendo, con motivo del asunto de la promiscuidad de los asientos en las juntas de este organismo y su temor de que el propio Villanueva presentara una representación al rey ${ }^{18}$. El centro de atención de estas polémicas lo ocuparía la formación y la profesión de arquitecto, que tuvo entonces un gran protagonismo en la vida académica.

Todo ello demuestra el auge, y el grado de autonomía y de distinción, que la profesión estaba adquiriendo en la Academia, al tener que ser considerada como una práctica artística peculiar, muy distinta a las demás Bellas Artes por su carácter eminentemente práctico, e imprescindible en las actividades sociales y económicas cotidianas. Además, la formación del arquitecto era bien específica, pues exigía un aprendizaje más complejo por la concurrencia de distintas ciencias, mucho más técnicas que las necesarias en la enseñanza de las otras disciplinas artísticas, con el estudio del dibujo como lenguaje propio y lugar de encuentro entre ellas, aunque con la existencia de claras diferencias en su empleo.

\section{LA OPINIÓN DE VENTURA RODRIGGUEZ}

Ventura Rodríguez contestó el 31 de marzo de 1781 al encargo de la junta del día 4 de ese mismo mes con un informe breve, cuyas propuestas resultan ser muy concretas y realistas. Se refirió en él tan sólo al título de académico de mérito de arquitectura, sin aludir a otros grados como, por ejemplo, el de maestro de obras. Así, se desentendió de los otros profesionales de este arte, ciñéndose exclusivamente a la pregunta formulada por la Academia ${ }^{19}$.

Como primera medida para regular los exámenes a este título propuso un condicionante ético-moral bastante en boga entonces: en primer lugar se debía suponer la chonradez, vida y costumbres» del aspirante ya fuera de Madrid o forastero. A ello seguía un necesario requisito burocrático-

18 García Melero, José Enrique, "Los orígenes académicos del "romanticismo histórico" español: malestar y crisis en torno a 1792", en Espacio, tiempo y forma, serie VII, núm. 5. Madrid, Revista de la Facultad de Geografía e Historia de la UNED, págs. 211-262, 1992.

19 Rodríguez, Ventura, Parecer a cerca de mejorar el modo de recibir los académicos de mérito. Madrid, 31 de marzo de 1781. 2 fois. AASF: leg. 17-3/1. Este manuscrito está publicado por UbedA De los Cobos, Andrés, Pintura, mentalidad e ideología en la Real Academia de Bellas Artes de San Fernando. 1741-1800. Tésis doctoral. Madrid, Servicio de Reprografía de la Editorial de la Universidad Complutense de Madrid, 1988. Véase el volúmen II, documentos, págs. 366368 . 
administrativo: habría de presentar un memorial o instancia al Secretario de la Academia, quien comunicaría tal pretensión en la primera junta ordinaria.

La propuesta de Ventura Rodríguez, en la práctica común a todos los profesores de arquitectura de la Academia, se basaba en la realización por parte del aspirante de tres ejercicios: las pruebas de pensado y de repente, y un examen oral en presencia de los examinadores sobre los diseños hechos.

Rodríguez se mostró muy minucioso en su parecer sobre el proceso del examen, analizándolo todo al detalle. Así, el secretario comunicaría al pretendiente el tema del dibujo de su invención a realizar, elegido en la misma junta ordinaria, en la cual se habia presentado su instancia. Una vez recibida la comunicación de este asunto por el interesado, debería acudir personalmente con los diseños hechos al viceprotector, quien se informaría de la calidad de los mismos en secreto ante los profesores de arquitectura y demás, que tuviera por conveniente para asegurarse de su perfección. Después le señalaría una fecha para el examen, de la cual el secretario avisaría el día anterior al aspirante, convocando al mismo tiempo a la junta.

El tribunal examinador tendría que estar formado según Ventura Rodríguez por siete miembros con derecho a voz y voto, quienes deberían llevar a la misma las distintas propuestas de preguntas a realizar. La integrarían todos los directores y tenientes de arquitectura, el director general, aunque no fuera arquitecto, y los académicos de mérito de este arte, que el viceprotector decidiera llamar hasta completar ese número. Podrían asistir a tal acto como testigos otros académicos de pintura y escultura, aunque no lo consideraba conveniente para lograr la «libertad del examinando".

Reunidos todos ellos junto al protector, cuando lo tuviera por conveniente, viceprotector, consiliarios, profesores y secretario, se sacaría a suerte un asunto, para que el aspirante lo dibujara en el término de dos horas. Transcurrido el tiempo de la prueba de repente el pretendiente presentaría su diseño en el estado que estuviera. Se le examinaría sobre este dibujo, el proyecto previo de pensado y acerca de las materias propias de su profesión tanto en la teoría como en la práctica por los profesores, quienes de dos en dos y en presencia de esa junta le harian preguntas. El examen duraría una hora, o más, si se juzgara conveniente, y hasta admitía la posibilidad de dejar para otro día su continuación en otras dos horas más. Después solamente los profesores de arquitectura, convocados al examen, darian su voto por escrito y firmado, siendo leídos 
por el secretario. La pluralidad del voto decidiría el mérito del pretendiente y en el caso de haberlo se le despacharía su correspondiente título.

\section{EL DICTAMEN DE MIGUEL FERNÁNDEZ}

Miguel Fernández, director de arquitectura desde 1774 y colaborador de Sabatini en las obras del Palacio Real de Madrid, fue bastante escueto en su opinión del 1 de abril de $1781^{20}$. Pensaba que los aspirantes al grado de académico de mérito deberían hacer los dibujos que la Academia les ordenase antes y no realizar los que quisieran, tal y como entonces ocurría. Además, tendrían que manifestar en dónde y por qué autores habian estudiado, ejecutar una prueba de repente y pasar por un examen. En su opinión se podría eximir de este último a aquellos individuos premiados en los concursos generales y a los pensionados en Roma, pues ya habian pasado por tales ejercicios.

Propuso hacer una diferencia clara entre los académicos extraordinarios, los de mérito, los directores y tenientes directores de la Academia y los maestros de obras. Consideraba una irregularidad que aquellos y estos últimos tuviesen las mismas facultades para elegir, medir y tasar las fábricas que los de mérito y los profesores. Por último, juzgaba conveniente que los aspirantes a ser académicos de arquitectura hicieran sus dibujos en alguna sala de la Academia, dándoseles dos o tres meses de tiempo para ejecutarlos.

\section{JUAN DE VILLANUEVA Y LA PROFESIÓN DE ARQUITECTO}

Juan de Villanueva contestó el 23 de abril de 1781 a la petición de la junta ordinaria, enviando su parecer junto con una carta dirigida a Antonio Ponz ${ }^{21}$. Pero en este mismo legajo con signatura 17-3/1 del Archivo de la Academia se conserva, además de este texto más breve, el extracto de otra representación suya, que, al parecer, debía ser de contenido bastante más extenso, resumido posteriormente por el secretario, quien en este

20 El dictamen de Miguel Fernández está datado en Madrid, el 1 de abril de 1781. AASF: $17-3 / 1$. Sobre este arquitecto vid. SAmBricio. Carlos, La arquitectura de la llustración. Madrid 1986, págs. 327-329. También: QuINTANA MARTínez, Alicia, La arquitectura y los arquitectos en la Real Academia de Bellas Artes de San Fernando (1744-1774). Madrid, Xarait, 1983.

21 VILlanUeVa, Juan de, Sentir sobre el nuevo arreglamiento, que se premedita establecer para la aprobación de Maestros de obras y Arquitectos, y la recepción de Académicos. 2 fols. Madrid, 23 de abril de 1781. AASF: leg. 17-3/1. 
manuscrito respetó párrafos enteros del original, que destacó entre comillas ${ }^{22}$. Tales documentos son, así pues, unos precedentes importantes del famoso informe sobre los estudios de este centro, redactado por el arquitecto del rey y fechado el 20 de julio de 1792, cerca de once años después, a los pocos días de haber sido nombrado Director General de la Academia ${ }^{23}$. Hay, sin duda, entre ellos semejanzas bastantes notables en muchos de los juicios expuestos, aunque en el manuscrito de 1781 Villanueva se mostró, o quiso ser en esta ocasión, más ortodoxo dentro del sistema académico que en el posterior.

Si Ventura Rodríguez, bastante más escueto y formalista, trató únicamente en su escrito del 31 de marzo sobre el método a emplear en los exámenes, a los que el aspirante al grado de arquitecto académico de mérito debería someterse para conseguir tal título, respondiendo, así, a la petición concreta de la junta, por el contrario Juan de Villanueva extendió su parecer también a la aprobación de los maestros de obras y de arquitectos, a la recepción de académicos y hasta a los oficiales de albañilería, canteros y carpinteros. El arquitecto del rey deseaba controlar académicamente los distintos empleos y oficios relacionados con la arquitectura y codificar las diferentes pruebas de acceso a tales grados. Sin embargo, aunque extendió su opinión en este sentido, planteó su parecer de una forma bastante más general, deteniéndose menos, tal y como Ventura Rodríguez hiciera antes, en los detalles más mínimos de los exámenes a realizar.

Ambos escritos de Villanueva son indudablemente testimonios muy representativos del afán academicista por controlar de una forma racional y metódica tanto el acceso como la práctica cotidiana de la profesión del artista dentro del código clásico. Estableció en ellos una auténtica escala de valores para jerarquizar por sistema el ejercicio del arquitecto en función de una mayor o menor capacidad intelectual en cada grado. Dos coordenadas diferentes, pero complementarias entre sí, ya tópicas y tradicionales, le sirvieron de referencia a la hora de codificar las profesiones y los oficios de la arquitectura: el binomio dicotonómico ya viejo existente

22 Extracto de un papel escrito por el Arqto. D. Juan de Villanueva, en orden a la distinción de Profesores de Arquitectura y al examen de ellos, según sus clases, en la Academia. (S. I. S. f. 1781). AASF: leg. 17-3/1. Al final del documento se puede leer lo siguiente: «N. Este papel parece se escribió cuando la Academia pidió a sus Profesores dictamen sobre el arreglo para el examen y la admisión de Académicos. $Y$ en una nota al fin de él se expresaba que no se presentó a la Academia por parecer largo, y que para este fin se hizo un extracto". Este comentario final debe ser de Isidoro Bosarte.

${ }_{23}$ Villanueva, Juan de, Informe sobre el estado de la enseñanza en la Academia. Madrid, 20 de julio de 1792,36 h., $20,5 \times 15$ C. AASF: leg. 18-1/1. 
El debate académico sobre los exámenes para las distintas profesiones de...

entre la teoría y la práctica, así como su encuentro, y la relación de diferencia y dependencia entre la actividad del intelecto y el quehacer manual.

Villanueva coincidía, así pues, tanto en su escrito del 23 de abril como en el extracto, con la junta ordinaria en la necesidad de reformar los estatutos de la Academia en todo lo referente a las aprobaciones de arquitectos y de maestros de obras, y en la recepción de académicos por considerar las pruebas, a las que entonces se les sometía, totalmente insuficientes y carecer de la extensión y claridad necesarias. Sin embargo, aunque sus escritos están en la línea académica tal vez por pura necesidad al tener que adecuarse a la ideología del organismo, que le pedía su parecer, no por ello dejaría de proponer en su informe personal una alternativa ciertamente revolucionaria en ese contexto del academicismo español. Así, tal y como se practicaba en Roma y en el resto de Italia, a donde había viajado como pensionado de la Academia entre los años de 1759 y 1764, era partidario de dejar, reproduzco aquí literalmente sus palabras, "obrar esta profesión con una entera libertad, y que los estudios, habilidad y mérito, según el vario juicio de las gentes, coloquen a los profesores en el grado que les corresponde, sin ser obligados a pasar por los exámenes, ni otras formalidades".

No obstante, Juan de Villanueva era totalmente consciente de que esta idea, aunque personalmente la consideraba más útil y decorosa, parecía irrealizable, una especie de utopía, al conocer a la perfección tanto al país como al organismo, en donde se hallaba. Su segunda alternativa por el contrario concordaba con la política ilustrada, absolutista y centralista de Carlos III en la línea de los Borbones y obviamente también se adecuaba con las directrices mismas de la Academia, que había pedido su parecer en tal sentido y no en otro distinto. Pero su propia ética le obligaba a ser siempre sincero consigo mismo y exponer previamente su verdadera opinión.

Por todo ello, y dentro de la ortodoxia obligatoriamente imprescindible, creia que este centro debia responsabilizarse de tal labor y establecer un auténtico reglamento bien ordenado con todas las precauciones posibles y necesarias para conocer a la perfección el mérito auténtico de los concursantes. Era necesario terminar para siempre con los favores y las protecciones excesivos, que se practicaban en este instituto. La Academia habría de atender en su reglamento, a que los profesores, recibidos por sus individuos, tuvieran un mérito sobresaliente respecto a los países, en donde se hallaban. Los aprobados para la ejecución de las obras estarían preparados para disponerlas, dirigirlas y realizarlas, a fin de que el público no padeciera ningún perjuicio. 
En este mismo sentido se manifestó en su informe más largo, cuyo contenido se puede conocer por el extracto conservado en el archivo de la Academia. Los estatutos debían extenderse y dárseles más explicación. Para Villanueva no era posible comparar la pintura y la escultura con la arquitectura por la variedad de sus estudios y ocupaciones. Los pintores y escultores estaban capacitados para dar a conocer todas sus habilidades con la presentación, simplemente, de un cuadro o de una figura de barro; pero ello sería imposible para un arquitecto. El proceso era más complejo en este sentido, pues no podía manifestar su suficiencia y la práctica necesaria para realizar una construcción, aunque mostrase dibujos ideados por él con buena disposición, gusto y solidez. Resultaba difícil saber con total seguridad la pericia del pretendiente por el examen, que a tales diseños se añadiera, aunque se realizara de una forma muy escrupulosa. Tal prueba solia reducirse a puntos concretos de la construcción, y al conocimiento y empleo de los materiales. De ella se concluiría su habilidad para disponer y dirigir prácticamente la obra, pero no así su vitruvianismo, formado con la lectura.

Villanueva admitia, dándola por hecho, en su informe original la existencia de dos categorías distintas entre los profesionales de la arquitectura: los arquitectos y los maestros de obras. Aquellos constituían, así pues, un cuerpo superior, porque debían poseer no sólo la teoría, sino también la práctica para lograr el conocimiento de la posibilidad y seguridad de lo que dispusieran. Se realizaba, por lo tanto, en ellos el concepto clásico del arquitecto, asumido por el clasicismo de la llustración, en el cual se conjugaban equilibradamente uno y otro conocimientos. Se necesitaba distinguir entre ambos grados tanto en el título o nombramiento de la Academia como en sus facultades y privilegios respectivos.

Era consciente, asi se manifiesta en el extracto, de que resultaba imposible que salieran los arquitectos sobresalientes suficientes para todo el reino. Sin embargo, pensaba que el crecido número de profesores medianos podría ser útil al público por la naturaleza, variedad e importancia relativas de las construcciones, que se realizaban en el país. Se les debia ocupar o en la dirección de las obras menores o en calidad de subalternos de otras más importantes, dirigidas por arquitectos de más habilidad y crédito. No obstante, he aquí una nota del clasicismo utilitario de Villanueva tan propio de la llustración, la Academia tendría la función de asegurar «la debida subordinación de los profesores menos instruídos, aunque útiles, a los más hábiles y experimentados».

Juan de Villanueva siempre se mostró en sus escritos como un auténtico político, preocupado por la profesión de arquitecto, su consideración social y sus salidas económicas. Buen conocedor de los objetivos 
de la Academia, en la que se había formado y con la experiencia transmitida por su hermano Diego ${ }^{24}$, estableció todo un sistema de exámenes distintos bajo su control, pues el rey la había concedido la enseñanza de este difícil arte, y el examen y aprobación de sus profesores. Partiendo, así pues, de unos hechos socialmente consumados y admitidos, y de la conveniencia a la causa pública, deseaba estratificar y jerarquizar a la perfección con el espíritu estamental de su época los distintos oficios y profesiones relacionados con la arquitectura. No se trataba, por lo tanto, de controlar tan sólo el título de arquitecto, tal y como había demandado la junta, sino también a cuantas personas intervinieran en la práctica de este arte. Quería que se estableciesen nexos y principios de subordinación entre ellos, diferentes privilegios, y derechos y obligaciones, para que nunca hubiera lugar a las dudas, y no se inmiscuyeran los unos en las tareas de los otros. $Y$ todo ello se haría siempre desde la Academia a través de la estratificación ya tradicional de tres clases distintas de profesionales: los maestros en los oficios de albañilería, cantería y carpintería, los maestros de obras y los arquitectos. $Y$ en el vértice de esta pirámide de la profesión habría que colocar a los académicos por la arquitectura.

En el fondo de su parecer predominaba la vieja idea de proteger por medio de distintos exámenes el título superior de arquitecto, cuya labor tan peculiar se estaba degradando al inmiscuirse en ella otros profesionales de la construcción menos cualificados y con la simple práctica en su campo específico de acción. No admitía, como escribió y se puede leer en el extracto, que "un material e ignorante albañil», que tal vez no supiera leer y escribir, se hallara cargado de obras y de riquezas, $y$, lo que era aún más grave, de “honor y estimación». Sin embargo, había entonces muchos arquitectos "sin proporción para ganar para zapatos". $Y$ todo ello entonces ocurría, aunque se habían sacrificado desde niños acudiendo a las clases de la Academia, ejercitándose en sus concursos y asistiendo a los estudios de los profesores hábiles y acreditados. Pensaba, así pues, con esa idea social y política tan propia de su época, que

24 Su hermano Diego de Villanueva presentó voluntariamente en 1768 a la junta particular de la Academia un "Plan de exámenes de arquitectura", fechado el 15 de octubre de ese año, que pasó por ia junta particular del 27 de noviembre. AASF: leg.: 28-2/1. Quiso dividir y especializar a los profesionales de la arquitectura, siguiendo el sistema pedagógico establecido en París por Blondel, que cita, en tres categorias diferentes: medidores, tasadores y directores. Cada una de ellas se correspondía con una de las distintas partes en que desde vitruvio se dividía la arquitectura: firmeza, comodidad y hermosura. En función de este sistema estableció distintos tipos de exámenes, que se relacionaban con un programa peculiar $\mathrm{v}$ de creciente complejidad. En este informe también manifestó la necesidad de traducir al castellano los tratados escritos en lenguas extranjeras y de reeditar los ya existentes en España. 
éste era el origen de la desestimación de tal profesión y de que las gentes acomodadas no enviaran a sus hijos a estudiar este noble arte, contrariamente a lo que sucedía en otros países.

Pero, aunque Juan de Villanueva jerarquizó en sus dos escritos por clases, y siempre en función de la habilidad y del mérito teórico-práctico, los distintos oficios y profesiones de la arquitectura, no deseaba establecer unos estamentos totalmente cerrados e inaccesibles entre sí. Procuró siempre dejar abiertas las posibilidades, de que los profesores mejor dotados de cada grado pudieran pasar a desempeñar la profesión superior correspondiente, aún marcando las distancias entre los arquitectos, como los profesionales de rango superior, y los maestros de obras y los demás oficios de la construcción, la base misma tan necesaria de esa pirámide.

No especificó, sin embargo, el cargo de aparejador, que en estos documentos aparece tratado de una forma desdibujada y hasta muy confusa, pues, aunque se les menciona en un par de ocasiones, no se indica su función específica ${ }^{25}$. Tal ocupación queda, así, en un campo de nadie, sin formar parte de una profesión específica dentro del escalafón jerárquico de las profesiones arquitectónicas, que Villanueva definió en estos documentos con una gran precisión. Posiblemente daba de esta forma a entender la persistencia en su época de la función siempre ocasional de este puesto durante el siglo XVII, sin lograr alcanzar aún ninguna especificidad absoluta. Su desempeño quedaba abierto tanto a los arquitectos jóvenes como para los maestros de obras, con los que a veces se confunden, e incluso accesible para los discípulos menos dotados de este arte, o formados en las clases nocturnas de la Academia alternando el estudio con el trabajo por ineludible necesidad económica y social.

En realidad, hasta que Pedro de Silva escribiera sus reflexiones sobre el estudio de la arquitectura en la Academia, este organismo no se había ocupado del empleo de aparejador. El consiliario se mostraba partidario en este discurso, cuyo manuscrito está fechado ya el 6 de noviembre de 1792, de acabar de una vez para siempre con el puesto de maestro de obras y de diferenciar únicamente entre el arquitecto y el aparejador. La existencia de esas dos categorías admitidas por la tradición, que por lo común tan sólo se distinguían en tanto en cuanto el uno se ocupaba de la realización de obras grandes, y el otro de las casas y de las más

25 Sobre la figura del aparejador durante el siglo xvil es muy importante el libro de GARCíA MORALES, María Victoria, El oficio de construir: Origen de profesiones. El Aparejador de el siglo XVII. Madrid, Colegio Oficial de Aparejadores y Arquitectos Técnicos de Madrid, 1990. Véase también el prólogo del profesor Víctor Nieto Alcaide a este libro. 
pequeñas, era a su juicio el origen de competencias, dudas y fraude, que con seguridad ocasionarían que el arquitecto, llegado un momento, no tuviera que comer. El aparejador sería en su opinión el simple ejecutor de los pensamientos de este último, dominando los oficios de albañil, cantero y carpintero, y sabiendo delinear, pero sin la necesidad de poseer para ello un gran primor. Pensó que los discípulos de las clases nocturnas de la Academia eran las personas ideales para desempeñar este puesto, pues, debido a que trabajaban, no podrían alcanzar los progresos necesarios exigibles a un arquitecto ${ }^{26}$.

A fin de hacer mucho más clara esta jerarquización profesional, Juan de Villanueva estableció distintos tipos de exámenes, que, obviamente, se complicaban en extensión y profundidad en función siempre de su clase superior. Dos principios básicos valorarían estos ejercícios: los estudios y la asistencia a las clases de la Academia, y la experiencia práctica adquirida en la casa de los profesionales mejor dotados, que les proporcionaba cierto grado de cualificación.

Villanueva se ocupó de un modo tan sólo formalmente diferente de los distintos exámenes a realizar para el acceso a las diversas clases de profesionales de la arquitectura en el manuscrito original y en el extracto de otro suyo al parecer bastante más extenso y minucioso. Sin embargo, se pueden leer muchas veces parecidas e incluso las mismas frases, citadas literalmente, en ambos documentos. Todo ello parece demostrar, que el arquitecto del rey debió escribir primero este último y más tarde áquel; lo resumió después en sus líneas principales, pero aprovechó en ocasiones su redacción original. Si en el manuscrito breve jerarquizó dichas clases a partir de los grados superiores para terminar con los inferiores, en el resumen conservado los términos se invertirían, pues abordó en primer lugar los oficios manuales de la arquitectura.

\section{EL ARQUITECTO SEGÚN VILLANUEVA}

El empleo de arquitecto fue analizado por Juan de Villanueva en cierta forma siempre en contraposición con el de maestro de obras. Ya se ha indicado antes como en su pensamiento se realiza perfectamente el con-

26 Reflexiones de Pedro de Silva sobre los estudios de Arquitectura de la Real Academia de San Fernando. Madrid, 6 de noviembre de 1792. AASF: Leg. 18-1/1. Este documento lo estudié en "La Real Academia de San Fernando en 1792", "Juan de Villanueva y los nuevos planes de estudio", op. cit., y en "Arquitectura y burocracia: el proceso del proyecto en la Comisión de arquitectura de la Academia», op. cit. 


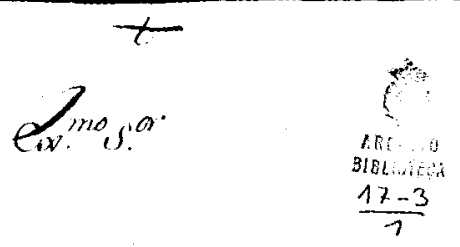

dist

$318 L, \ldots i t i n$

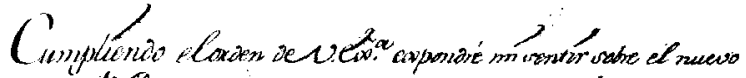

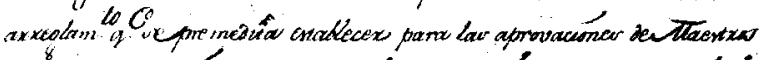

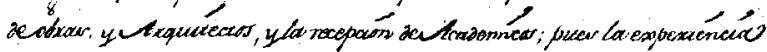

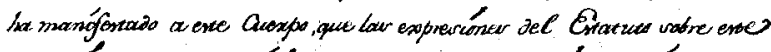

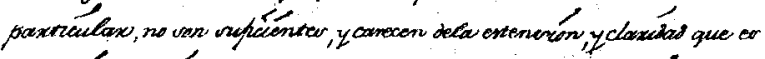

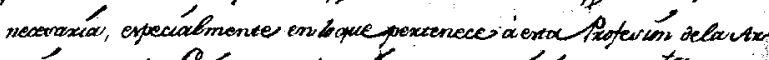

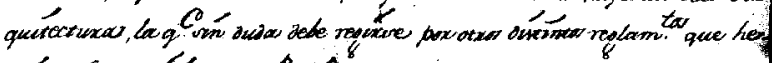

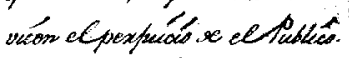

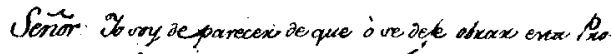

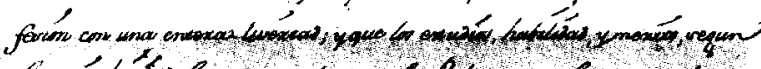

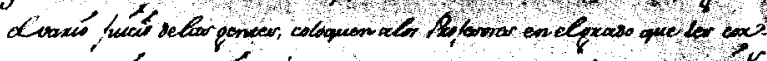

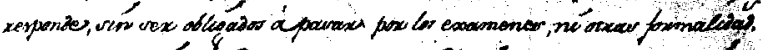

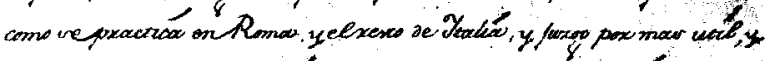

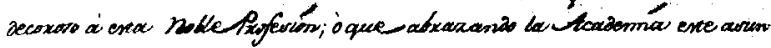

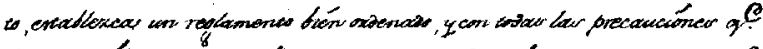

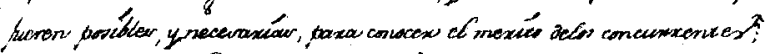

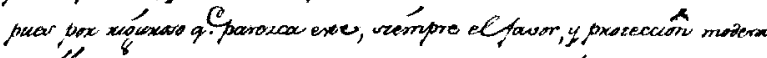

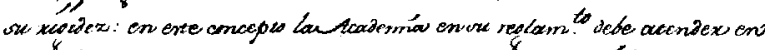

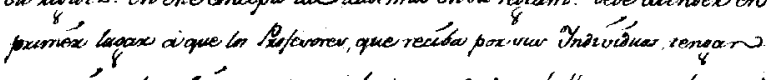

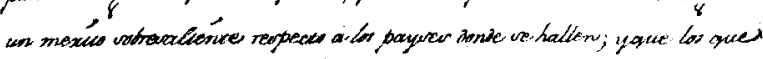

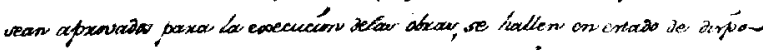

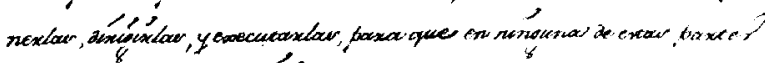
el publés paseaca pextucios.

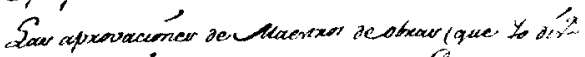

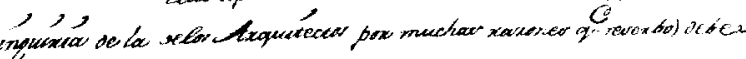
ming

Fig. 3. «Sentir de Juan de Villanueva sobre el nuevo arreglamiento para las aprobaciones de Maestros de obras y Arquitectos, y la recepción de Académicos». Madrid, 23 de abril de 1781. A.A.S.F.: Leg.: 17-3/1, fol. 1 anv.-2 anv. 


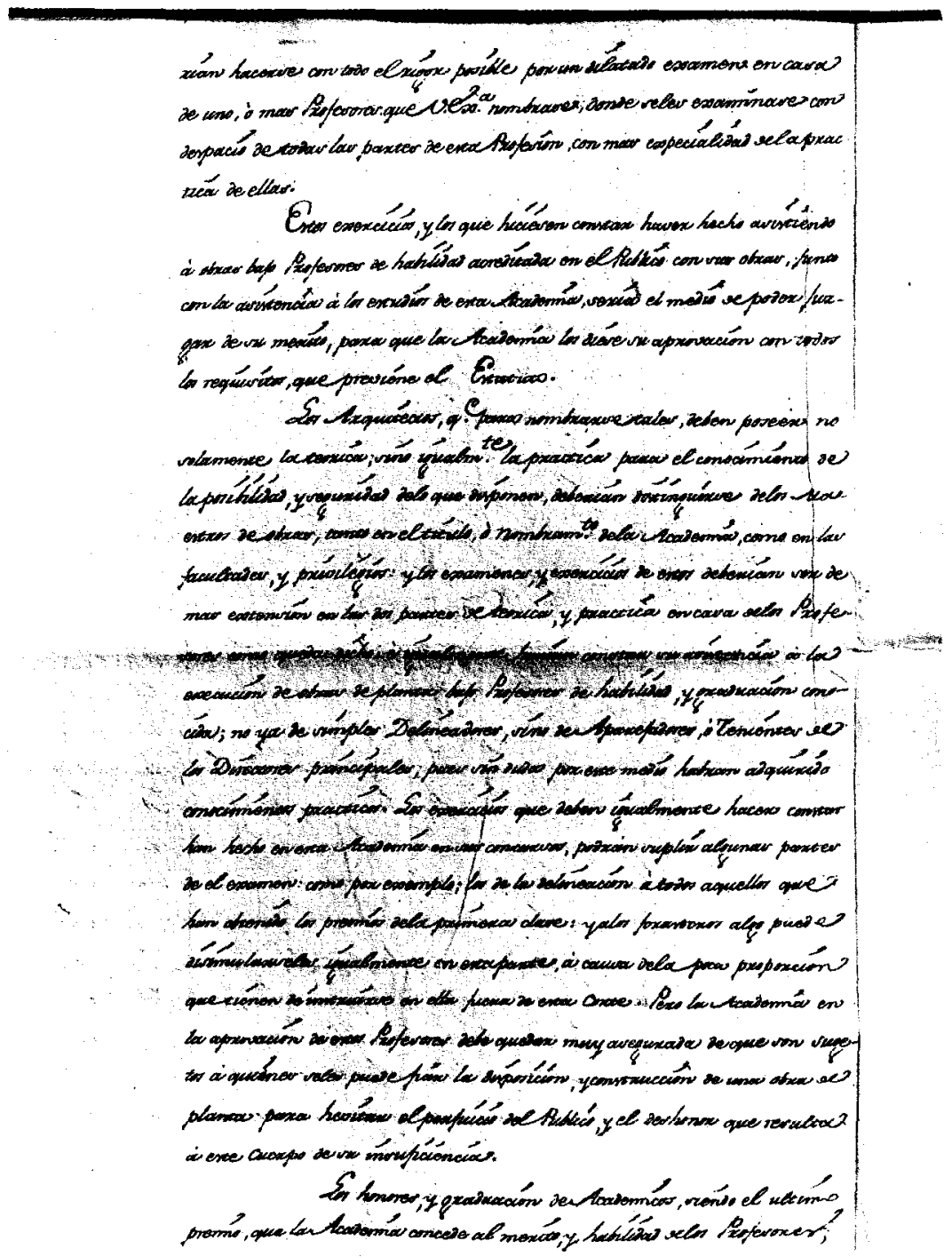

Fig. 4. "Sentir de Juan de Villanueva sobre el nuevo arreglamiento para las aprobaciones de Maestros de obras y Arquitectos, y la recepción de Académicos». Madrid, 23 de abril de 1781. A.A.S.F.: Leg.: 17-3/1, fol. 1 rev. 


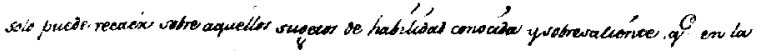

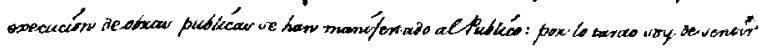

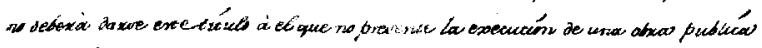

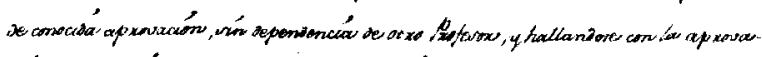

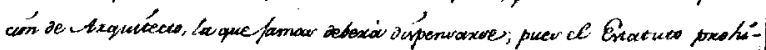

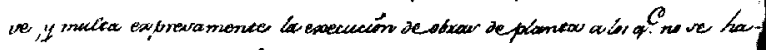

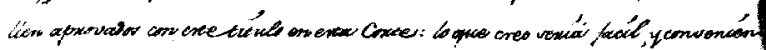

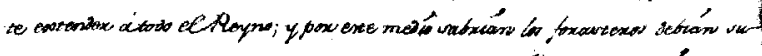

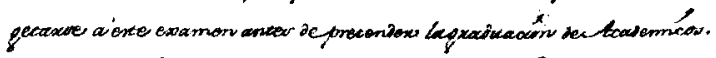

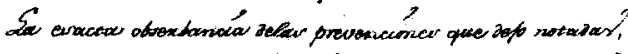

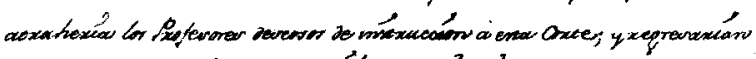

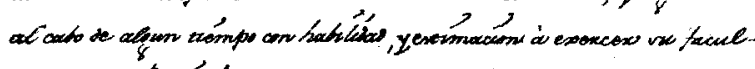

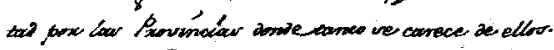

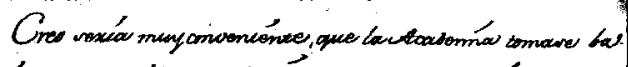

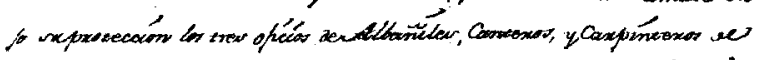

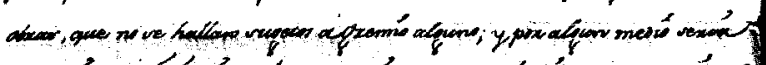

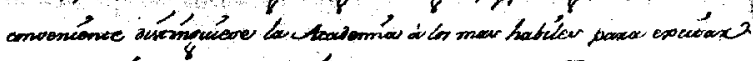

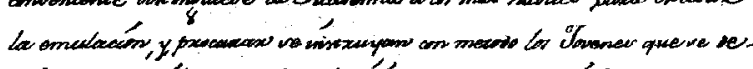

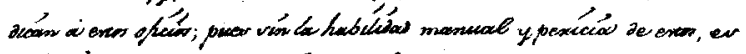

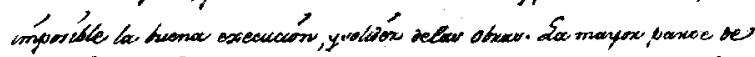

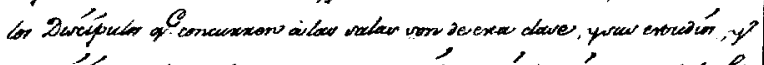

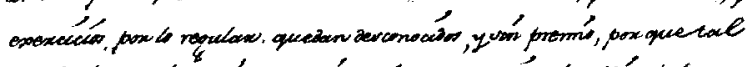

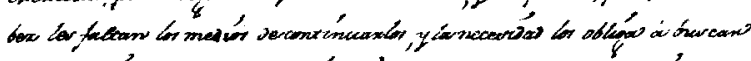

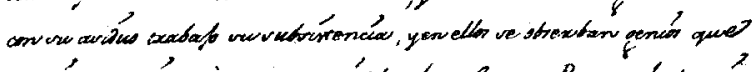

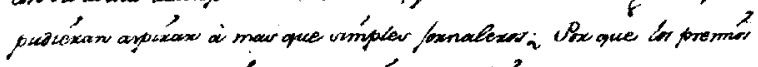

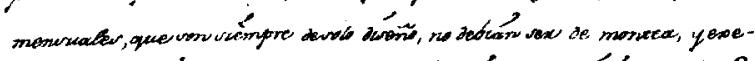

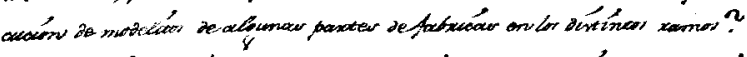

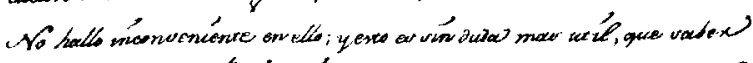

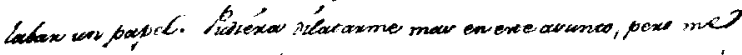

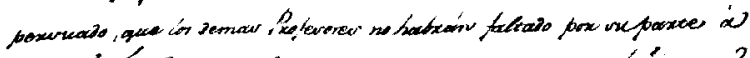

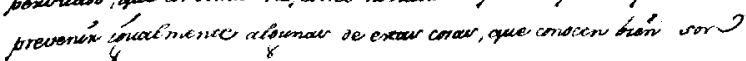

Fig. 5. "Sentir de Juan de Villanueva sobre el nuevo arreglamiento para las aprobaciones de Maestros de obras y Arquitectos, y la recepción de Académicos». Madrid, 23 de abril de 1781. A.A.S.F.: Leg.: 17-3/1, fol. 2 anv. 
El debate académico sobre los exámenes para las distintas profesiones de...

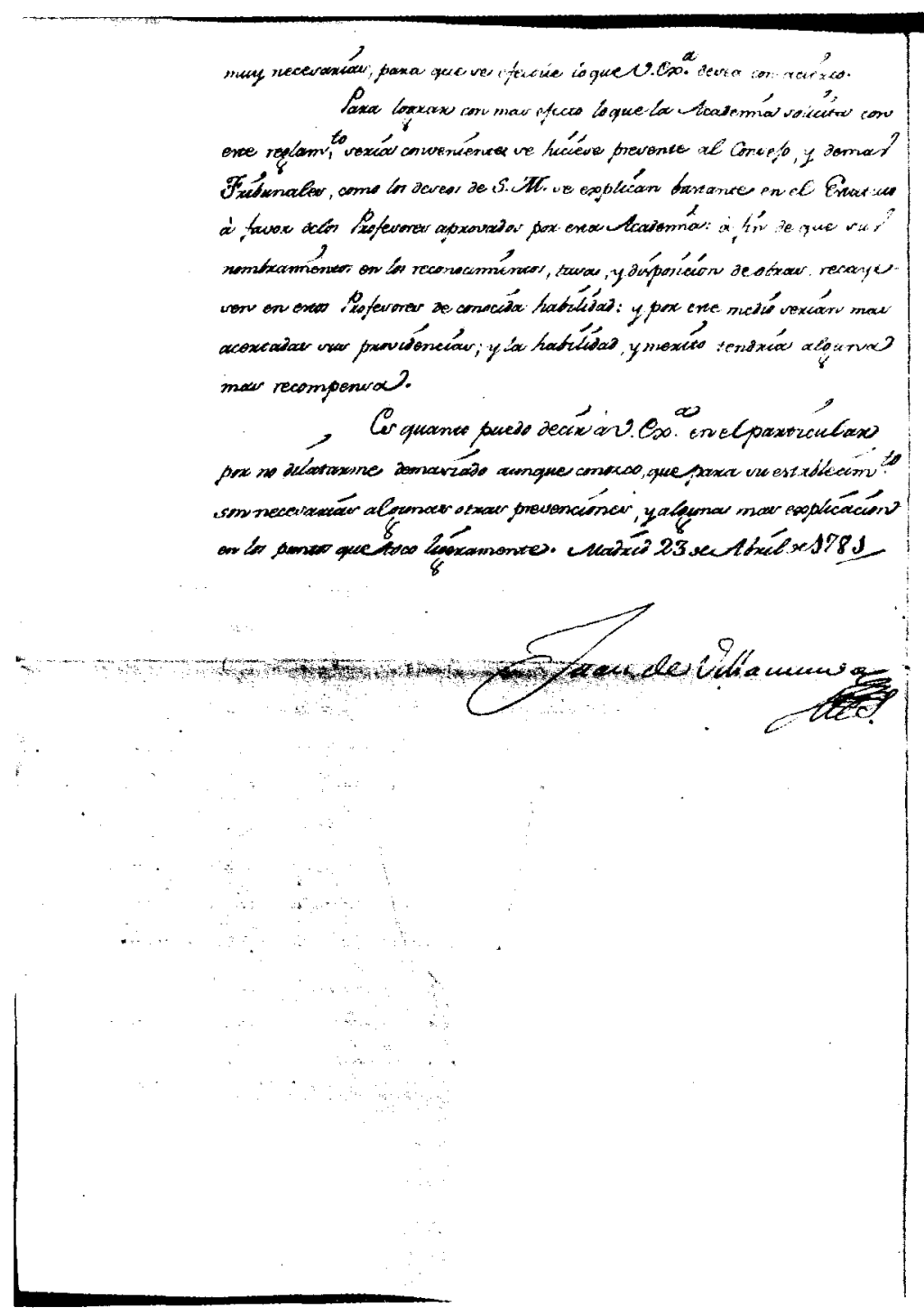

Fig. 6. "Sentir de Juan de Villanueva sobre el nuevo arreglamiento para las aprobaciones de Maestros de obras y Arquitectos, y la recepción de Académicos". Madrid, 23 de abril de 1781. A.A.S.F.: Leg.: 17-3/1, fol. 2 anv. 
cepto clásico de esta profesión con el encuentro equilibrado entre una formación teórica y otra práctica, sin que ninguno de estos dos aspectos predominase sobre el otro. Pero el componente conceptual era precisamente el elemento, que le diferenciaría con claridad del maestro de obras, a quien se le consideraba, sobre todo, como un simple practicón. $Y$ en base de esta peculiaridad quería establecer una distinción bien clara no sólo en el título, o nombramiento de la Academia, sino también $-y$ esto es lo fundamental- en las facultades y privilegios respectivos. Así pues, Villanueva juzgaba el empleo de arquitecto como «más profundo, más calificado y de mayores estudios teóricos y prácticos". Por tal motivo se manifestó en el extracto partidario de tratar esta clase tan específica de una forma bien distinta de las demás profesiones relacionadas con la arquitectura.

Pero, aunque Juan de Villanueva parecía no dudar de la posibilidad, de que algunas veces se formaran arquitectos hábiles sin más carrera y estudio que la sola práctica, creía imposible, no obstante, que adquirieran de esta forma la valía y extensa instrucción necesarias. Según pensaba, el futuro arquitecto debía basar sus conocimientos en el aprendizaje de las matemáticas y del dibujo, en la lectura de los mejores autores, acudiendo a la Academia y destacándose en sus concursos. Pero también tendría que ir al estudio de un profesor acreditado, quien siempre le instruiría de viva voz y con el ejemplo, así como en todas aquellas "prevenciones y noticias" precisas para conseguir dicha práctica, que no se lograrían en las escuelas de la Academia. Era necesaria su asistencia a la ejecución de obras de planta realizada por profesores de habilidad y graduación reconocidas. No debían ser simples delineadores, sino aparejadores o tenientes de los directores principales. De este modo el nuevo arquitecto estaría capacitado para disponer y dirigir obras de planta por sí solo.

Por consiguiente, Juan de Villanueva parecía querer distinguir entre una formación teórica, proporcionada sobre todo en los medios académicos, y esa otra instrucción especulativa, adquirida de una forma especial en el estudio de un arquitecto de prestigio reconocido, quien al mismo tiempo le enseñaría y le mandaría, siéndose ambos respectivamente útiles entre si. $Y$ este concepto parece derivar de la pervivencia inconsciente, 0 tal vez meditada, de la antigua formación de base gremial, al conjugarse, así, lo medieval y viejo, el gremio aún persistente en muchas ciudades españolas, con to nuevo, la Academia. Sin embargo, este centro docente siempre sería el responsable último en la otorgación definitiva del título de arquitecto por medio de una prueba final. También se encontraban en esta propuesta la enseñanza quizás más colectiva academicista con la individualizada del taller. 
Juan de Villanueva coincidía en lo fundamental con Ventura Rodríguez a la hora de exponer el método a emplear para examinar a los aspirantes a la clase de arquitecto. No obstante, pasó por alto ese inicial e imprescindible componente ético-moral, que el maestro de Ciempozuelos parece que consideraba importante. En su lugar el autor del edificio para Gabinete de Ciencias Naturales imponía un requisito profesional en su opinión totalmente necesario: la presentación de certificados de académicos 0 arquitectos, con los que se demostraba el orden de sus estudios teóricos y prácticos bajo la dirección de profesores aprobados en obras de planta.

Como Ventura Rodríguez, Juan de Villanueva propuso dos ejercicios diferentes para conseguir ese título: las pruebas de pensado y de repente. En la primera se daría al aspirante el tema de un edificio para que lo dibujase, comprobándose después su pericia en el otro examen. Se dispensaria de aquel ejercício a quienes hubieran ganado un premio general de primera clase. A continuación se le preguntaría sobre todos aquellos aspectos teóricos y prácticos, que intervienen en la arquitectura en base a una concepción totalmente clásica, vitruviana. Se le examinaría de asuntos tales como de la disposición, idea y buen gusto de los edificios; sobre la variedad de las construcciones y de los materiales; acerca de la economía y solidez de los edificios, y sobre los remedios de sus sentimientos y ruinas.

Por último, la Academia, una vez informada sobre la pericia del examinado por tales pruebas, votaría en junta ordinaria su aprobación por pluralidad de votos. El título sería despachado con las necesarias «formalidades de estilo", dándosele una serie de facultades específicas, que le diferenciaban con claridad de los maestros de obras. Tendrían, así, la potestad de disponer, dirigir y ejecutar obras de planta por sí solo, sin dependencia de otros profesores. De igual forma se le darian los mismos privilegios y facultades concedidos a los académicos supernumerarios, aunque sin la posesión de este título, ni asiento en las juntas generales, ni voto consultivo. La Academia también le otorgaría licencia, para que se valiera de los maestros de obras y de los oficios arquitectónicos, que necesitase, aunque no estuvieran aprobados. Tendría la capacidad de habilitarlos sólamente para sus obras bajo su propia responsabilidad y firma. Independencia en su actividad y capacidad de dirección eran, quizás, las notas más caracterizadoras de la profesión de arquitecto.

\section{EL ACADÉMICO EN ARQUITECTURA}

Tal y como parece ser obvio, Villanueva pensaba, que se debía exigir en primer lugar para conseguir el título de académico supernumerario y 
de mérito, el último grado académico al que se podía aspirar, el ser antes arquitecto aprobado por los medios preceptivos, requisito indispensable para cualquier aspirante sin ninguna excepción. Opinaba que tan sólo recaería en sujetos de habilidad reconocida y sobresaliente en la ejecución de una o más obras, ideadas y dirigidas por sí solo sin dependencia de otro profesor. Por lo tanto, serían los créditos adquiridos por el arquitecto con el público y con los profesores su principal examen, en todo lo tocante al buen gusto, pericia y proceder adecuado. Para lograrlo tendría tan sólo que presentar a la Academia el diseño de un edificio público de conocida aprobación, sujetándose después a unas ligeras preguntas. La junta votaría la concesión de tal título en función de este examen, de la exhibición de certificaciones de obras ejecutadas según sus diseños y bajo su dirección, y los informes solicitados por la Academia de profesores acreditados sobre la autenticidad de tales documentos y acerca de la buena disposición según su clase, gusto y solidez, con que las obras alegadas estuvieran construidas.

No obstante, Villanueva también preveyó en el resumen de su documento más largo la posibilidad, de que este grado también se concediera a «un señor o sujeto de carácter», que, aunque no ejerciera la arquitectura, pudiera tener un mérito suficiente para este título por su estudio teórico y buen gusto. En tal sentido admitía, aunque aquí tan sólo dedicó una mención bastante breve, la existencia de los señores y eruditos 0 «literatos" en la Academia.

\section{EL MAESTRO DE OBRAS: SUS FACULTADES Y LIMITACIONES}

Si en el documento original de Juan de Villanueva se dedica poco espacio a la profesión de maestro de obras, siempre subordinado al título de arquitecto, no ocurre de esta forma en la síntesis de ese otro manuscrito más extenso. Partía de la idea de la distinción clara entre ambas profesiones por varias razones, que se reservaba enigmáticamente expresar ahora. En el primero de estos textos indicaba cómo la aprobación de este grado debería hacerse con todo el rigor posible por medio de un examen dilatado en casa de uno o más profesores, nombrados por el viceprotector. Serían examinados despacio de las partes distintas de esta profesión y, sobre todo, de la práctica de ellas. Así, su mérito sería juzgado por medio de ese examen, y de las certificaciones de haber asistido a las obras bajo profesores de pública habilidad y a los estudios de la Academia.

Pero en la síntesis del documento más extenso, tal y como ya se ha indicado antes, se preveía la posibilidad de acceder a esta clase de maes- 
tro de obras por parte tanto de los maestros más hábiles de las artes edificatorias de albañilería, cantería y carpintería como de aquellos discípulos de la Academia, que, no habiendo hecho los mayores progresos, hubieran servido de aparejadores y adquirido alguna mayor instrucción que los antecedentes. Los prácticos se examinarían de las artes de los tres oficios antes indicados y también presentarían certificados de arquitectos 0 académicos de haber servido de aparejadores en obras públicas y privadas de planta, y otros de los dueños de las obras o arquitectos, que avalasen las ejecutadas por sí solos. De la misma forma deberían hacer constar el haber asistido a la Academia. En el examen, realizado por dos directores o tenientes de arquitectura nombrados por este organismo, se les preguntaría sobre los temas siguientes: acerca del diseño, montea, medida, tasa, distribución de trabajos en todos los ramos, que se incluyen en las obras, sus reparos, apeos, remedios, calidad de materiales, su distinta manipulación y clases de obras. Los examinadores informarían formalmente a la Academia, siendo votada su aprobación en junta ordinaria según los estatutos.

Por el título, o despacho de maestro de obras dado, se le otorgaba la facultad de reconocer, medir y tasar todo remiendo o reparo, y de disponerlos y ejecutarlos en todos los ramos, que comprenden una fábrica. Sólo los aprobados podrían tomar los asientos de las obras de planta, prohibiéndose expresamente esta labor a los que no lo hubieran sido antes. Pero no podrían de ninguna manera ni medir, ni tasar, ni dirigir obras de planta sin haber sido aprobados arquitectos, a no ser que lo hiciera bajo la dirección y subordinación a alguno o varios de estos profesionales superiores. De esta forma Villanueva señalaba una distinción y una subordinación clara entre ellos, aún concediéndoles los privilegios que según los estatutos gozaban los discípulos premiados de la Academia. El despacho les permitía el poder ejercer libremente su profesión por todo el Reino, dejando muy clara la idea de no tener que sujetarse a gremio alguno.

\section{LA APROBACIÓN DE LOS MAESTROS EN LOS OFICIOS ARQUITECTÓNICOS}

Villanueva deseaba que la Academia se ocupara de la formación y del examen de los maestros en los tres oficios arquitectónicos de albañilería, cantería y carpintería, porque no estaban entonces incluidos en ningún gremio, ni se hallaban sujetos a ningún tipo de aprendizaje formal peculiar, causa por la cual poseían una gran libertad, que consideraba como muy perjudicial al bien público. Este defecto era el motivo, de que no existieran 
en España buenos oficiales, ya que aprendian con independencia y sin ningún tipo de método. Tampoco le parecía justo que tales oficiales subalternos se encontraran exentos de las leyes, que obligaban a arquitectos y maestros de obras a examinarse.

Una vez más la experiencia práctica es para Villanueva un requerimiento indispensable antes de poder presentarse al examen. Así, los oficiales de estas tres artes deberían para poder tener derecho a examinarse de maestros en sus oficios respectivos presentar certificaciones de arquitectos o maestros de obras, en cuyas construcciones hubieran servido algunos años de aparejadores u oficiales. He aquí una vez más la indefinición del puesto de aparejador, que, al parecer, podía ser ejercido indistintamente por arquitectos, maestros de obras, discípulos de la Academia y oficiales. Pero, además, se les exigía el estar matriculados en este centro y el informe de sus profesores los directores y tenientes de su aprovechamiento en la Geometría y su inteligencia en el dibujo geométrico.

Para su examen bastaba en opinión de Juan de Villanueva la presencia de un solo director o teniente director nombrado por la Academia, que le examinaría en su propia casa, y al parecer sin testigos, de la Aritmética, Geometría, valores, montea, delineación, replanteo sobre el terreno, calidad de los materiales, su manipulación, empleo y calidad de obras pertenecientes a sus respectivos oficios. Tal evaluación no constaría tan sólo de simples preguntas, sino también de las operaciones prácticas, que fueran posibles realizar.

La Academia le expediría certificado de maestro en el oficio correspondiente después de haber sido informada por el examinador de su suficiencia especialmente en la práctica. Así, quedarían autorizados para poder tasar, medir y ejecutar toda obra de su oficio, no pudiendo realizar ni apeos ni obras de planta. También se les concederían los privilegios otorgados a los discípulos de la Academia según los estatutos, y quedarían exentos de ser examinados y de pertenecer a gremio alguno fuera de la Corte.

Villanueva pensaba, que por medio de este sencillo procedimiento se podrían tener oficiales y maestros en esos ramos, que también estarían capacitados para servir de aparejadores, puesto, que a su juicio, entonces tanto escaseaba en España. Además, dejaba abierta la posibilidad en el caso de ser sobresalientes de acceder a una graduación superior en esta escala jerárquica. De esta forma, con una visión política y social muy adecuada, propia del pragmatismo educativo de la época de la llustración, deseaba que la Academia distinguiese siempre a los maestros más hábiles de estas artes edificatorias para ejercitar, asi, la emulación y procurar que 
los jóvenes se instruyeran con método. Pensaba que, sin la habilidad y la pericia de tales profesionales, resultaría totalmente imposible lograr las imprescindibles buena ejecución y la solidez de las obras...

\section{JUAN DE VILLANUEVA EN LA ACADEMIA}

Estos dos manuscritos de Juan de Villanueva de 1781 son junto con los otros dos de 1792, el del 24 de agosto sobre la disciplina de los discípulos de la Academia ${ }^{27}$ y el informe más importante del 20 de julio acerca de los estudios de este centro ${ }^{28}$, y la representación debatiendo a Antonio de Varas del 17 de enero de $1793^{29}$ los principales textos del arquitecto conservados en el archivo de la Academia. Demuestran una indudable actividad teórica y política en este centro docente, quehacer centrado sobre todo en los temas educativos, en la configuración de este organismo y en la profesión de arquitecto. Pero Villanueva no realizó este quehacer académico de una forma continuada, tal y como hicieran otros profesores como, por ejemplo, Pedro Arnal, sino espaciadamente en algunos de los momentos más críticos de la historia de este organismo del último cuarto del siglo XVIII. No se to permitió su importante labor como arquitecto práctico, actividad que le tuvo muy ocupado en la realización de los diseños de los edificios más importantes construidos en España durante el reinado de Carlos IV.

Para darnos cuenta del interés de estos escritos es conveniente establecer brevemente aquí una noticia documentada de su paso por la Academia, en la que permaneció prácticamente a lo largo de toda su vida, pero siempre de un modo bastante irregular. Para ello me valdré de varios documentos importantes conservados en el legajo 43-1/1 en un cuadernillo, que constituye su expediente académico ${ }^{30}$. De entre todos ellos des-

${ }^{27}$ Carta de Juan de Villanueva al SVP en la que le explica su opinión sobre los métodos apropiados para establecer cierta disciplina entre los jóvenes alumnos de los primeros cursos de la Academia, y le anuncia que cuando pueda elaborará un método para la enseñanza de la arquitectura. Madrid, 24 de agosto de 1792. 5 h. AASF: Leg. 18-1/1.

${ }_{28}$ Informe de Juan de Villanueva sobre el estado de la enseñanza en la Academia. Madrid, 20 de julio de 1792, 36 h. AASF: Leg. 18-1/1.

29 Informe que presentan Juan de Villanueva, Pedro Arnal, Manuel Martín Rodríguez, Francisco Sánchez y Manuel Machuca y Bargas al viceprotector de la Academia, sobre el discurso de Antonio de Varas y Portilla respecto a la instrucción del arquitecto, el estado de las matemáticas y la arquitectura, y los medios para mejorar los estudios de la Academia. Madrid, 17 de enero de 1793. 29 h. AASF: Leg. 18-20;1.

30 En el legajo 43-1/1 se encuentra un cuadernillo muy interesante sobre Juan de Villanueva y su actuación en la Academia de San Fernando. Incluye documentación datada entre 1767 y 1811. Los manuscritos más importantes son una carta de 4 folios del arquitecto dirigida al 
taca, sin duda, su breve autobiografía escrita el 20 de mayo de 1792 , enviada a Isidoro Bosarte, como respuesta a la petición de este secretario de datos de su actividad en el centro, que completaran los obtenidos en su búsqueda por los libros de acuerdos del archivo, necesarios para informar a las juntas particular y general con motivo de la votación al empleo de director general, al cual aspiraba junto con Pedro Arnal ${ }^{31}$. También hay que destacar aquí una interesante noticia necrológica, que se conserva manuscrita en este archivo, redactada al morir en 1811 en plena dominación de José Bonaparte ${ }^{32}$.

Juan de Villanueva, que nació en Madrid el 15 de septiembre de 1739 , inició la breve noticia autobiográfica de su paso por la Academia, refiriéndose inicialmente a la actividad de su padre el escultor del mismo nombre, como uno de los primeros profesores desde la junta preparatoria de 1744, y a su hermano Diego, que fue teniente director de arquitectura desde el 12 de abril de 1752 y su maestro en esta disciplina. Comenzó sus trabajos y ejercicios académicos como uno de sus discípulos más antiguos ya en 1754 a la edad de catorce años, obteniéndo un galardón el 22 de diciembre de este mismo año en el concurso general de premios convocados por el primer protector José de Carvajal por su proyecto de planta y alzado de la fachada de una cárcel de Corte, así como en los sucesivos del 25 de enero de 1756 (primer premio de la segunda clase) por el diseño del patio de un palacio y del 6 de febrero de 1757, en donde logró el primer premio de la primera clase por el dibujo de planta y alzado de un convento con su iglesia y dependencias. En esta misma fecha fue agregado a la delineación del Palacio Real bajo la dirección de su hermano Diego de Villanueva.

Concurrió al concurso convocado el 20 de abril de 1758 para elegir a los pensionados en Roma, consiguiendo la pensión por oposición con la totalidad de los votos al diseñar una casa de campo para un grande de España con sus jardines y oficinas en planta general, particular, fachada y corte. Allí permaneció junto con el arquitecto Domingo Lois de Montea-

secretario Isidoro Bosarte con fecha de 20 de mayo de 1792, dándole noticias personales sobre sus méritos académicos, y la noticia necrológica de 5 folios con la biografía del arquitecto.

31 Hay en el legajo 43-1/1 un manuscrito firmado por Isidoro Bosarte titulado "Méritos de D. Juan de Villanueva", redactados en función de la carta de este arquitecto dirigida a ese secretario, y de los asientos y libros de la Academia.

${ }_{32}$ He completado algunos datos en base a la imprescindible monografía de Fernando Chueca Goitia y Carlos de Miguel, La vida y las obras del arquitecto Juan de Villanueva. Ampliado y corregido por Fernando Chueca. Madrid, Gráficas Carlos-Jaime, 1949. Obra fundamental es también MOnLé́n Gavilanes, Pedro: La arquitectura de Juan de Villanueva: Madrid, COAM, 1988. 
gudo bajo la dirección de Francisco Preciado de la Vega hasta 1764, algunos meses después de que se le terminara dicha beca "estudioso y aplicado", - según se dice en su necrología- «bebiendo en aquellas únicas y profundas fuentes de las Artes cuanto bueno y apreciable hallaba, como lo califican las muchas obras, que remitió a la Academia, y aún existen en sus Salas, disipando por tal medio el mal gusto churrigueresco". Dibujó entre otros edificios el arco de Tito y el templo de orden corintio de la Sibila en Tívoli y los de Júpiter Stator y Júpiter Tronante.

Vuelto a Madrid, "sin opción ni destino alguno en esta Corte, pues aún le escaseó la Academia el honor que concedía a los demás pensionados", por orden de la Academia viajó a Granada bajo la dirección de José de Hermosilla y en compañía de Pedro Arnal, trabajando en el levantamiento de planos y alzados en la Alhambra y sepulcros de los Reyes Católicos entre el 18 de septiembre de 1766 y el 7 de abril de $1767^{33}$.

En la junta del 8 de noviembre de 1767 se le nombró académico de mérito en atención a la "conocida habilidad, aplicación y mérito de este profesor y al particular contraido en los dibujos de Córdoba y Granada", substituyendo a Francisco Subirás en la Sala de Geometría durante un curso completo ${ }^{34}$. Pero en el verano de ese año marchó a San Lorenzo de El Escorial en calidad de sobreestante del padre obrero de este Real Sitio, sirviendo a los padres jerónimos. Desde 1768 trabajó para los infantes, diseñando la casa del cónsul de Francia y la del Marqués de Campovillar, así como las del Príncipe de Asturias y del infante D. Gabriel, y la del Marqués de los Llanos.

El 11 de agosto de 1774, al poco tiempo de morir su hermano Diego y al ascender Miguel Fernández al empleo de director, fue nombrado teniente director de arquitectura por real orden firmada por el Marqués de Grimaldi ${ }^{35}$. Durante algunos años asistió con cierta regularidad a la Sala

33 Sobre el viaje de José Hermosilla, Juan de Villanueva y Pedro Arnal a Granada es imprescindible el libro siguiente: Rodriguez Ruiz, Delfín, La memoria frágil. José de Hermosilla y las Antigüedades Árabes de España. Madrid, Fundación Cultural COAM, 1992.

${ }_{34}$ El 8 de noviembre de 1767 Juan de Villanueva envió una instancia a la Academia pidiendo

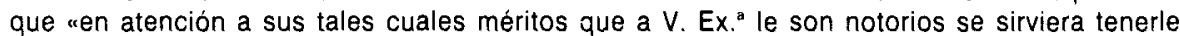
presente para honrarle en lo que tuviese por más conveniente». En el margen de tal instancia se leé: "La Academia en atención a la conocida habilidad, aplicación y mérito de este profesor y al particular contraido en los dibujos de Córdoba y Granada le concede la graduación de Académico de mérito". AASF: leg. 43-1/1.

${ }_{35}$ Real orden, firmada por el Marqués de Grimaldi, dirigida a Ignacio de Hermosilla, secretarıo de la Academia, indicándole que el rey «ha venido en nombrar para servir esta tenencia de Teniente Director de Arquitectura a Juan de Villanueva, propuesto por la Academia en primer lugar y a consulta suya del 8 de agosto". La Real Orden pasó la junta particular del 4 de septiembre de 1774. AASF: leg. 43-1/1. 
de Geometría de la Academia, cuando le correspondía y siempre que sus continuos viajes y asistencias a las comisiones del rey y de los infantes en los Reales Sitios se lo permitieron. Es precisamente en estos años cuando redactó los dos documentos estudiados en este trabajo.

Pero en noviembre de 1784 se sintió en la obligación de solicitar al conde de Floridablanca, entonces protector, que se le conservara la clase de académico de mérito, y de pedir, que fuese dispensado de la asistencia a la enseñanza ${ }^{36}$. Propuso una alternativa para conseguirlo: o que se nombrara a otro arquitecto en su empleo, para que desempeñase este puesto, prescindiéndose, así, de él, o que simplemente se le diera su sueldo, con el fin de que le sustituyese en sus clases. La junta particular del 5 de diciembre aceptó como más conveniente la segunda propuesta. De esta forma, acordó designar a Manuel Martín Rodríguez, para que impartiera su enseñanza, con la cesión del sueldo de teniente director, empleo que, no obstante, Juan de Villanueva conservaría de forma oficial con la facultades correspondientes de acudir a las juntas y de poder vo$\operatorname{tar}^{37}$.

Tal decisión fue comunicada el 18 de diciembre al discípulo de Ventura Rodríguez en un oficio firmado por Antonio Ponz, como secretario de la Academia. Manuel Martín Rodríguez contestó el día 22 de ese mismo mes aceptando la designación, pero, siendo de su mayor interés la distinción con que este centro le había dignado honrarle, no admitía de ninguna manera el sueldo que correspondía a Juan de Villanueva. Sin embargo, no le debió satisfacer plenamente esta propuesta, que le proporcionaba los honorarios y la obligación de dar clases, como si fuera teniente director de arquitectura; pero sin los honores y derechos de representación correspondientes a tal empleo. Así, escribió lo siguiente en su carta de aceptación dirigida a Ponz: "pero así espero que, así como me honra con el cargo de asitir a la enseñanza de la Geometría por dicho Señor Villanueva, del mismo modo me dispense la gracia de concurrir con voz y voto a

36 Oficio del Conde de Floridablanca, fechado en San Lorenzo el 20 de noviembre de 1784 , dirigido a Antonio Ponz. Le indica en él que Juan de Villanueva había solicitado por medio de un memorial que la Academia eligiera y nombrara a un profesor de su satisfacción, para que constantemente diera en sus salas la enseñanza que le correspondía como Teniente Director de Arquitectura, cediéndole el sueldo que distrutaba por este empleo, o que, dándolo por vacante se confiriera a quien pudiera servirlo. AASF: leg. 43-1/1.

${ }_{37}$ Carta de Antonio Ponz dirigida a Juan de Villanueva; fechada el 17 de diciembre de 1784. Acusa recibo en ella de la suya y le comunica que la junta particular decidió conservarle el título de teniente director de arquitectura y elegir a quien le supliría con su sueldo. Juan de Villanueva le contestó el 18 de diciembre de 1784, agradeciéndole el honor de conservar su grado y diciendo que asistiria a todas las juntas, que pudiera. AASF: leg. 43-1/1. 
todas las juntas ordinarias, por parecer anexo al cargo que se me confiere, para poder dar cuenta en ellas de lo que ocurra, como se previene en el párrafo 3 del capítulo 13 de los estatutos» ${ }^{38}$.

La petición de Manuel Martín Rodríguez fue estudiada en la junta particular del 2 de enero de 1785, siendo rechazada. El día 4 de ese mismo mes Ponz le contestó comunicándole lo acordado. La Academia se mantenía en su idea, pues el estipendio a percibir era ya asunto tratado y concluido, debiéndo cobrarlo la persona que diera la enseñanza con la alternativa establecida. La junta no se encontraba con las facultades necesarias para convocarle a todas las reuniones de la Academia, porque la plaza de teniente director no estaba vacante. Su provisión, cuando la estuviese, correspondía al propio rey. Juan de Villanueva, al quedar con la misma graduación que tenía, debía ser convocado por acuerdo a todas las juntas. No obstante, se llamaría a Manuel Martín Rodríguez cuando asi se juzgara conveniente ${ }^{39}$.

El discípulo de Ventura Rodríguez volvió a ratificarse en su carta del 6 de enero de 1785 en lo dicho, renunciando a percibir dicho sueldo, que en su opinión correspondía a Villanueva al retenérsele los honores de teniente director. Se ofrecía a asistir pronto a la enseñanza.

Antonio Ponz en su oficio al conde de Floridablanca del 20 de enero le informaba de todo lo acordado por la junta particular de la Academia sobre este asunto ${ }^{40}$. También indicó que se había elegido a Manuel Martín Rodríguez para sustituirle, porque, además de ser uno de los antiguos académicos de mérito y de tener una notoria habilidad, concurría en él la circunstancia de que acababa de regresar de hacer un viaje a su costa por toda Italia con la finalidad de conseguir un mayor aprovechamiento y de adquirir nuevas luces en su profesión. Todo lo cual pareció muy bien al rey, según indicaba el protector en su oficio del 25 de febrero dirigido a ese secretario ${ }^{41}$.

38 Carta de Manuel Martín Rodríguez dirigida a Antonio Ponz, fechada el 22 de diciembre de 1784, aceptando el empleo; pero pidienúo condiciones según el párrafo 3 del capítulo 13 de los Estatutos de la Academia. AASF: Leg. 43-1/1.

39 Borrador de la carta de Antonio Ponz dirigida a Manuel Martín Rodríguez, fechada el 4 de enero de 1785. Le indica que leyó su carta del 22 de diciembre en la junta particular del 2 de enero de 1785. Le comunica a continuación lo acordado en ella. AASF: Leg. 43-1/1.

40 Oficio de Antonio Ponz dirigido al protector Conde de Floridablanca. 20 de enero de 1785. AASF: Leg. 43-1/1

41 Oficio del protector Conde de Floridablanca dirigido a Antonio Ponz, indicándole la aceptación real de lo acordado por la Academia en su junta particular. 25 de febrero de 1785. AASF: Leg. 43-1/1. 
Al morir Ventura Rodríguez en 1784, vacó la plaza de director de arquitectura, y antes de cubrirse Juan de Villanueva fue nombrado el 29 de diciembre de 1785 director honorario con precedencia de asiento al actual más antiguo de su arte a instancia y consulta de la Academia y en atención a su distinguido mérito y a las graves ocupaciones que le impedían asistir a los estudios, sin que lo hubiera pedido ${ }^{42}$. Aquel empleo fue otorgado en la junta ordinaria del 8 de enero de 1786 a otro arquitecto, a Pedro Arnal, quien le había acompañado a Granada para dibujar la Alhambra bajo la autoridad de José de Hermosilla. Obtuvo 17 votos secretos, mientras que uno fue para Manuel Martín Rodríguez y otro para Francisco Sánchez ${ }^{43}$. No se pronunció allí el nombre de Villanueva. El nombramiento fue confirmado por el protector el 20 de febrero. Por otra parte, Martín Rodríguez ocupó con plenos derechos, tal y como él deseaba, la plaza de primer teniente director de arquitectura ${ }^{44}$, mientras que poco después Francisco Sánchez era designado segundo teniente director de este ramo.

Hay que situar a Juan de Villanueva en este contexto de la Academia, entre Arnal y Martín Rodríguez, nombrado para un cargo honorífico y en cierta forma ahora marginado, así, _también se inhibió él mismo de las tareas docentes- de la vida académica. Este hecho quizá se debiera en primer lugar a sus obras en los Reales Sitios y, también, a que entonces estaba muy ocupado en la realización de los proyectos para el edificio de Gabinete de Ciencias Naturales por designación del propio conde de Floridablanca. Del mismo modo es preciso señalar aquí que sucedió a Ventura Rodríguez en 1786 como arquitecto y fontanero mayor del ayuntamiento de Madrid. Esta situación de éxitos fuera de la Academia y de aislamiento en ella debió generar cierta animadversión de Villanueva hacia

42 El nombramiento de Juan de Villanueva como director honorario fue tratado durante el otoño de 1785 en varias juntas particulares de la Academia. En las actas de la junta particular del día 6 de noviembre se dice: "Di cuenta de una respuesta del Sr. Protector a la que le escribí de orden de la junta sobre nombrar a D. Juan de Villanueva, Director honorario, atendiendo a sus ocupaciones, o preguntarle a éste si se halla en estado de servir como Director, para gobernarse en la propuesta de la plaza vacante. S. Ex. ${ }^{a}$ dejaba a arbitrio de la Junta el resolver según creyese justo y conveniente a favor de las Artes..." AASF: 3/123, fol. 318 rev. Su nombramiento como director honorario fue leido en la junta particular del 8 de enero de 1786. AASF: $3 / 124$, fol. 1 anv.

A3 Actas de las juntas ordinarias del 8 de enero, 5 de marzo y 2 de abril de 1786. AASF: 85 3 , fol. 5 y 11 anv.

${ }^{44}$ En la junta particular del 5 de febrero de 1786 se acordó proponer a la ordinaria siguiente para ocupar esta plaza de teniente director de arquitectura por la promoción de Juan de Villanueva a la de director honorario, a los académicos Manuel Martín Rodríguez, Francisco Sánchez y José Moreno, a fin de que fueran votados de forma secreta. AASF: $3 / 124$, fol. 2 rev. El nom bramiento de Martín Rodriguez se notificó en la junta particular del 2 de abril de 1786. AASF: $3 / 124$, fol. 5 anv. 
sus compañeros los arquitectos académicos, que de alguna forma le habían desplazado, y de un modo especial hacia Pedro Arnal, con quien competiría ya en 1792 por la plaza de Director General de este organismo. No obstante, en 1786, en el mismo año de la creación de la Junta de la Comisión de Arquitectura fue nombrado uno de sus vocales, pero sus muchas ocupaciones no le permitieron asistir sino a tres de las catorce reuniones celebradas durante ese año.

Pocos dias antes de cumplirse el 5 de abril de 1792 el segundo trienio del entonces director general de la Academia el escultor Manuel Alvarez, que había sido prorrogado en este empleo por real orden del 5 de abril de 1789, se decidió en la junta particular del 1 de abril proceder a la propuesta de un arquitecto para el desempeño de este puesto, pues tocaba a un profesor de arquitectura ocuparlo según definía sobre las alternativas en el estatuto XXV, fol. 61 . En la reunión del 6 de mayo se acordó designar a Juan de Villanueva, entonces director honorario, y a Pedro Arnal, director de continua asistencia, para que uno de ellos fuera elegido. Asimismo, se decidió convocar una junta general para graduarlos a pluralidad de votos secretos y consultar después al rey. Esta se celebró el 25 de mayo. Expuestos los méritos de cada uno de ellos por el secretario se procedió a la votación secreta, obteniendo de los 58 vocales asistentes 35 votos Juan de Villanueva y 23 Pedro Arnal. Villanueva fue nombrado por real orden del 29 de mayo director general de la Academia, empleo del cual tomó posesión en la junta ordinaria del 3 de junio, así como del asiento que le correspondía: el primero a la izquierda del viceprotector $^{45}$.

Así, Juan de Villanueva fue nombrado director general, nombramiento que muy posiblemente contradijo los deseos de los demás arquitectos de la Academia, quienes es muy posible que consideraran a Pedro Arnal como más adecuado para ocupar este cargo por su dedicación continua a este organismo.

\section{LA OPINIÓN DE PEDRO ARNAL}

El dictamen de Arnal se halla en la misma línea concreta, directa y discreta que el de Ventura Rodríguez. Dista, por lo tanto, mucho de la brillantez intelectual y de la elocuente minucia de los informes de Juan de Villanueva, que están muy bien escritos y perfectamente estructurados

45 Actas de la junta ordinaria del 3 de junio de 1792. AASF: 85-3, fol. 201 anv. 
y meditados, buscando siempre la reglamentación exhaustiva de las distintas profesiones de la arquitectura. Así, Arnal demuestra en este documento muy poca capacidad de redacción, y rudeza y torpeza en su expresión escrita.

Pedro Arnal inició su informe señalando la necesidad de la supresión de la clase de académico supernumerario. Constituían este estamento todos aquellos individuos, que no habían sido capaces de obtener el título de académico de mérito, que es el que les nombraba y graduaba por arquitecto, al carecer de la suficiencia imprescindible. Por lo tanto, era inadecuado que ambos cuerpos gozasen de los mismos privilegios y facultades. Pensaba que no se podía exponer el honor de este centro de las Bellas Artes con tales sujetos, faltos de la mínima capacidad exigible.

Arnal era partidario de realizar unos exámenes muy rigurosos para conseguir el grado de arquitecto, pues por cualquier descuido se podía causar la ruina del sujeto que confiara sus intereses en él. $Y$ en base a esta exigencia estableció un reglamento muy similar al de Ventura Rodríguez. En primer lugar el pretendiente debía presentar un memorial al protector o viceprotector. En la junta siguiente se señalaría el día en el que se le daría el tema a diseñar. El tribunal examinador estaría formado por dos consiliarios, dos académicos de honor, dos pintores y otros tantos escultores, así como por los profesores de arquitectura, siendo presidida por el viceprotector y el secretario. El aspirante habría de ejecutar para una mayor formalidad el asunto señalado por esta junta en la primera jornada encerrado en la misma Academia, tal y como lo hacian los opositores a las pensiones de Roma. Así se evitaría que el tema elegido se trasluciera y el pretendiente fuese prevenido.

Una vez ejecutada la obra se presentaría a ese tribunal. Si tuviera el mérito necesario, se le examinaría durante dos horas, en junta ordinaria y en presencia de toda la Academia, en particular, sobre su realización $y$, en general, acerca de las reglas de la buena arquitectura establecidas por los autores más acreditados. También se le preguntaría sobre la práctica y la teoría de la construcción en todos los ramos, que un buen arquitecto debería saber, así como de las matemáticas y de las demás ciencias aplicadas a este arte. La junta podría votar su recepción con pleno conocimiento, después de que los profesores de arquitectura expusieran su dictamen.

Arnal pensaba que en la aprobación de maestros de obras se debería seguir el método, que se empleaba hasta entonces; pero distinguiendo perfectamente su examen del de los arquitectos para que el público no los confundiese y percibiera las diferencias existentes entre ellos. Este 
equívoco iba en desdoro de la arquitectura, pues a su juicio tal profesional era un oficial de albañilería instruído sólo en la construcción.

Aconsejaba en su dictamen que la Academia velara a fin de que los tribunales no eligieran para realizar o construir las obras a nadie, que no fuera respectivamente arquitecto o maestro de obras aprobados por este organismo, pues entonces se elegían a sujetos sin este título. Estos estaban abusando de la situación y hacían construcciones de gran entidad.

\section{LA MODERACIÓN EN LOS EXÁMENES DE JOSÉ MORENO}

El matemático José Moreno, quien en 1786 al crearse la Junta de Comisión de Arquitectura fue nombrado por real disposición su primer secretario hasta su fallecimiento el 5 de enero de 1792, firmó su informe el 6 de mayo de $1781^{46}$. Le inició indicando que, aunque los sabios dictámenes dados por los arquitectos le producian veneración, presentaba respetuosamente el suyo sin aspirar a ninguna competencia ni moverle otro anhelo que el de obedecer los preceptos del protector. Era una forma de justificar su elección para este menester aún siendo persona ajena a la enseñanza de la arquitectura en la Academia.

Destacó que la admisión de los individuos de la Academia era asunto preferente para este organismo entre sus muchas ocupaciones. Por tal razón esta gracia habría que conferirse con «suma circunspección, equidad y miramiento" tanto por responder a la confianza del rey como por el propio crédito del centro, pues al admitirlos les calificaba, haciéndose fiadora de sus aciertos.

José Moreno consideraba que las razones anteriormente expuestas, aunque servían globalmente para el conjunto de las artes, eran sobre todo aplicables a la arquitectura, pues estaba destinada no sólo al buen gusto como sus compañeras, sino también a la comodidad y seguridad de los pueblos. Además, su práctica suponía a los profesores el conocimiento de muchas otras ciencias, sin cuyos auxilios se exponian «a malgastar, y si así cabe decirlo, a defraudar, a hacerse responsables de los caudales que les confien en la buen fe de estar calificada su suficiencia con el honroso título de ser individuos de la Academia".

El matemático José Moreno pensaba que, en tan importante asunto como era el de los exámenes a arquitectos, no se debía fiar exclusiva-

46 El "pensamiento" o dictamen de José Moreno, fechado en Madrid el 6 de mayo de 1781, se halla en AASF: Leg. 17-3/1. 
mente de las certificaciones y los testimonios, que no siempre merecian crédito. No obstante, se manifestó en el dictamen como partidario de realizarlos de una forma moderada para no desanimar a muchos, de los que estudiaban las artes, con la esperanza de participar algún día de las gracias dispensadas por la Academia.

Moreno estableció como primera condición para conseguir el título de arquitecto la de presentarse siempre el pretendiente al examen, fuera cual fuese su lugar de residencia. Previamente habría de entregar un memorial a la junta ordinaria de la Academia. Tal examen constaría de tres pruebas diferentes: de repente, de pensado y sobre la teoría y la práctica de la arquitectura.

El matemático y también arquitecto pensaba que se debía elegir para examinar al aspirante el diseño de un asunto "moderado, que exigiendo algún estudio de solidez, comodidad y hermosura", se pudiera poner en limpio en doce o quince días útiles. Deseaba, así, al pensar en los forasteros, evitar los perjuicios a los pretendientes de detenerlos mucho tiempo en esta labor.

La prueba de repente se realizaría, después de comunicado el tema y sobre un papel firmado por el viceprotector y secretario, en el término de dos horas. Pasados doce o quince días acudiría a una sala de la Academia a pasar a limpio ese diseño en papel también firmado y sin más auxilios que su instrumental y algún que otro libro, que pidiera. No podría realizar innovación alguna esencial en el pensamiento ni tampoco introducir ni sacar borrador ni papel alguno.

José Moreno distinguió para realizar el tercer ejercicio entre los aspirantes foráneos y los forasteros. En este último caso, si el viceprotector considerarse oportuno no detenerle por más tiempo, se podría convocar una junta de arquitectos; pero, si residía en la Corte, se presentaría en la próxima ordinaria de dos en dos. Se le examinaría con preguntas oportunas tanto sobre su obra como acerca de la teoría y de la práctica de las demás partes de su facultad.

Moreno concedió bastante importancia al protocolo de votación para conceder al aspirante el título de arquitecto. Los examinadores darían su dictamen por escrito y a su vista el viceprotector preguntaría a la junta si "merece o no merece ser propuesto para Académico". La pluralidad de votos decidiría su aprobación o suspenso como académico de mérito, y de existir empate el viceprotector decidiría. Pensaba, además, que sin necesidad de derogar el estatuto de los académicos supernumerarios, y con tan sólo no crearlos de esta clase, se lograría que no abusasen de los dictados y de las facultades correspondientes tan solo a los de mérito. 
Por último, José Moreno estableció la posibilidad de eximir de tales pruebas a todos aquellos individuos que por alguna particularidad fueran acreedores del favor de la Academia. Así, habría que tratar de un modo distinto a aquellos aspirantes discípulos suyos que a quienes no lo habian sido, aunque el estatuto estableciera de alguna forma diferencias entre ellos, al necesitar los unos tan sólo la pluralidad de los votos y los otros las dos terceras partes de ellos. Su idea era la de promover al grado de académicos de mérito a quienes hubieran conseguido la pensión en Roma, concediéndoles la antigüedad desde el mismo día de su obtención.

\section{EL DICTAMEN FINAL DEL CONSILIARIO PEDRO DE SILVA}

Antonio Ponz, secretario de la Academia, leyó un extracto escrito por él mismo de los distintos informes de los profesores de arquitectura sobre la forma de conceder en el futuro, el honor de académico en la junta particular del 11 de agosto de 1782. Se acordó en ella pasar todo el expediente a Pedro de Silva, consiliario y académico de mérito de Arquitectura, para que redactara un dictamen antes de realizar la consulta al rey por medio del protector, el primer Secretario del Estado ${ }^{47}$.

Pedro de Silva envió su dictamen en borrador por falta de tiempo para copiarlo a Ponz con algún retraso. Estaba inseguro de su calidad, pues le decía: “con eso también V.S. tendrá que disimular, porque no será sola la molestia para el cuerpo de la Academia en oir un mal dictamen, sino también para V.S. en leer de mala letra». El secretario lo leyó en la junta particular del 3 de noviembre de 1782. A pesar de la pesimista autocrítica de Silva, fue aprobado porque comprendía las principales razones anteriormente expuestas por los profesores y establecía, además, una regla justa, que ni hacía demasiado ardua la obtención del honor de académico ni tampoco resultaba muy fácil. Pero, además, proponía un método suficiente, para que constase a la Academia el mérito verdadero de los pretendientes $^{48}$.

Silva como consiliario, participante en las juntas particulares de la Academia, y académico de arquitectura, parecía tener la última palabra en el debate entablado, tal y como lo poseería más tarde en 1792 en la polémica

\footnotetext{
${ }^{47}$ Actas de las juntas particulares. (1776-1785). Actas de la junta particular del día 11 de agosto de 1782, fol. 232 rev. y 233 anv. AASF: $3 / 123$.

${ }_{48}$ Actas de las juntas particulares. (1775-1785). Actas de la junta particular del 3 de noviembre de 1782 , fols. 238 anv. -240 vuelta. AASF: $3 / 123$. Se incluye todo el dictamen de Pedro de Silva.
} 
entablada entre los arquitectos y el matemático Antonio de Varas. Así, su informe se redactó después de haber leído detenidamente los escritos de los demás profesores. Por lo tanto, su juicio es en cierta forma una simple síntesis, aunque a veces crítica, de los distintos pareceres de los arquitectos.

También hay que considerar este documento del 2 de noviembre de 1782, que originó casi directamente la real orden del 15 de enero de 1783, como un claro precedente de sus reflexiones fechadas diez años después, el 6 de noviembre de $1792^{49}$. Se recordará aquí que fueron redactadas con motivo del fracasado debate para la mejora del plan de estudio de arquitectura y en desagravio de los arquitectos, quienes habian sido ofendidos por el discurso del matemático Antonio de Varas, que fue leído en la junta extraordinaria del 28 de octubre de este año.

El aspecto más interesante del dictamen de Pedro de Silva de 1782 se halla en la contestación casi sistemática que más o menos explícitamente hizo de los informes de Juan de Villanueva, a quien, sin embargo, no cita. No era de extrañar que tales manuscritos del arquitecto le llamaran la atención por su minuciosidad, indudable calidad reflexiva, originalidad y gran extensión, que le diferenciaban, sin duda, de los demás. Así, frente a la previa, heterodoxa y sincera opinión de este arquitecto de "dejar obrar esta profesión con entera libertad, y que los estudios, habilidad y mérito, según el vario juicio de las gentes, coloquen a los Profesores en el grado que les corresponde, sin ser obligados a pasar por los examenes ni otras formalidades como se practica en Roma y en el resto de Italia» ${ }^{50}$, Pedro de Silva era partidario, haciéndose eco de la idea general de la Academia, de reglamentar perfectamente los exámenes para acceder a las distintas profesiones de la arquitectura. En este sentido, contestando a Villanueva, opinaba que «si la nación tuviera un cierto grado de gusto y conocimento, como le hay en Italia, yo convendría en que no hubiese examen alguno y a cada uno le recomendasen sus aciertos, que es, sin duda, lo más propio de la libertad de las Artes; pero esto que es practicable en Pintura y Escultura, donde no traen grave perjuicio los errores, sería en la Ar-

49 Reflexiones de Pedro de Silva sobre los estudios de Arquitectura de la Real Academia de San Fernando, 6 de noviembre de 1792. AASF: Leg. 18-1/1. Fue estudiado por García Melero, J. E., en "Juan de Villanueva y los nuevos planes de estudio", en Renovación. Crisis. Continuismo. La Real Academia de San Fernando en 1792. Madrid, Real Academia de Bellas Artes de San Fernando, 1992. Véase págs. 43-47.

so Sentimiento de Juan de Villanueva sobre el nuevo arreglamento que se premedita establecer para la aprobación de maestros de obras y arquitectos, y la recepción de académicos. Madrid, 23 de abril de 1781. Fol. 1 anv. AASF: Leg. 17-3/1. 


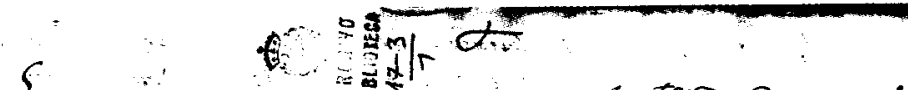

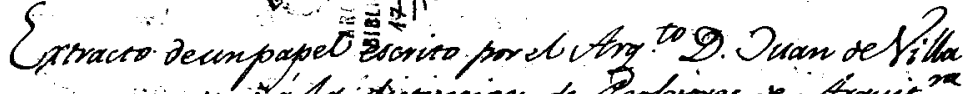

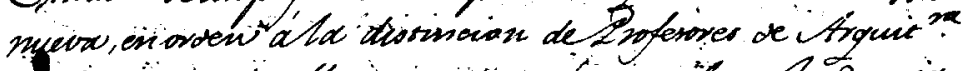

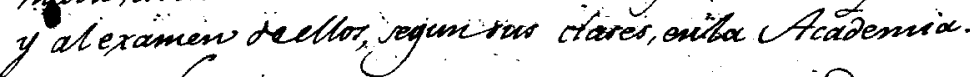
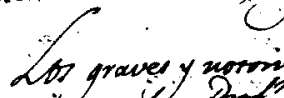

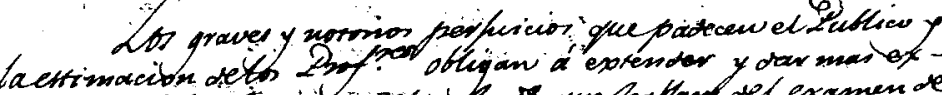

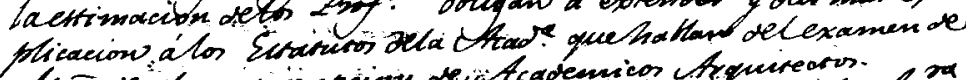

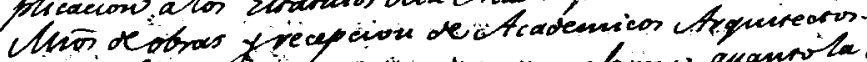

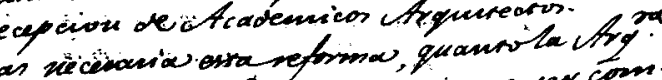

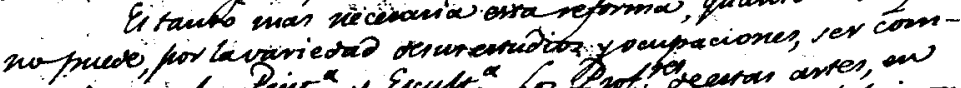

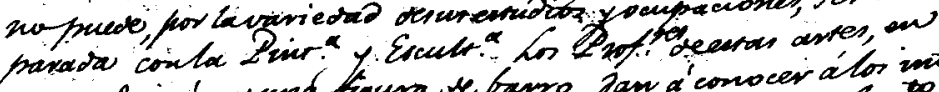
m quaso o' ew und fagura te barro, Law a'conocer álos inze-

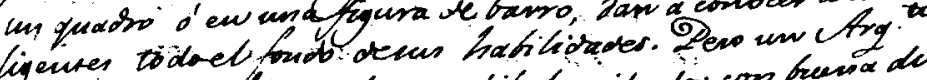

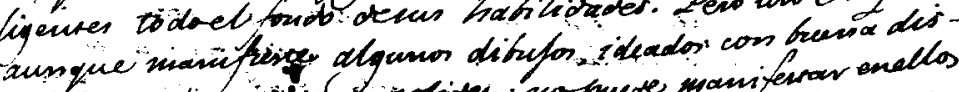

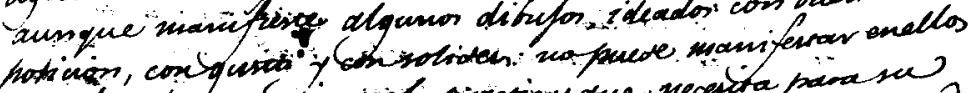

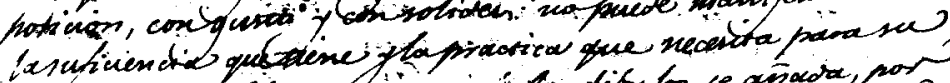

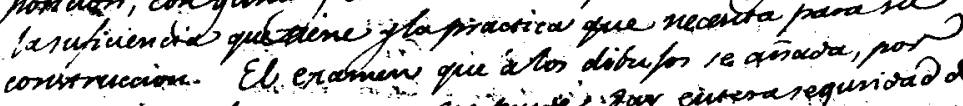

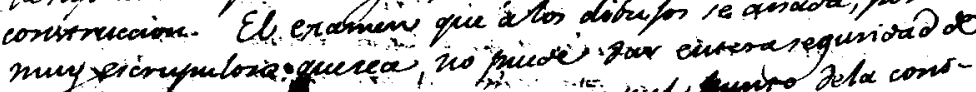

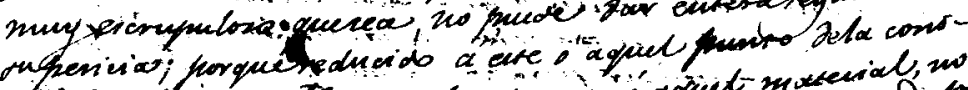

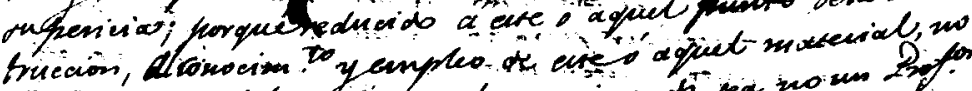

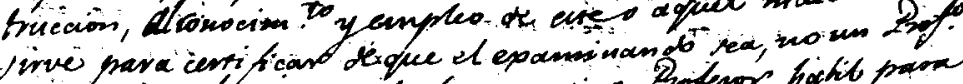

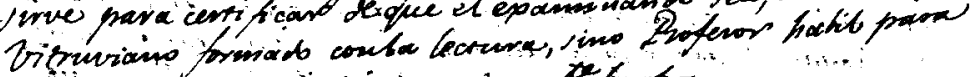

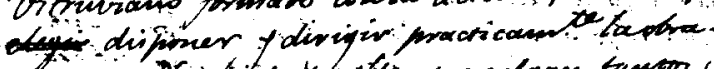

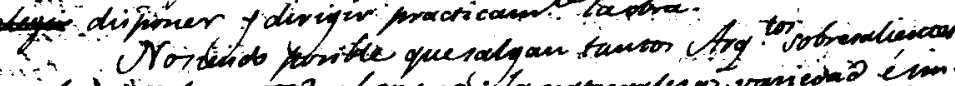

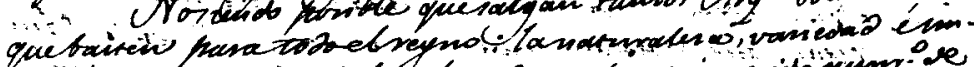

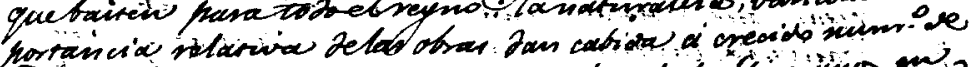

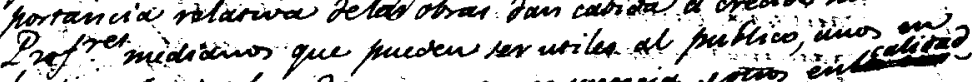

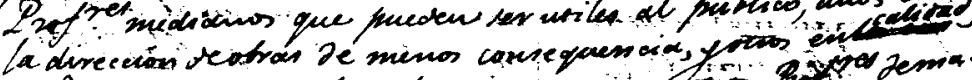

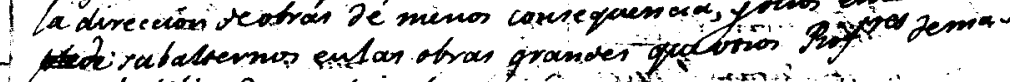

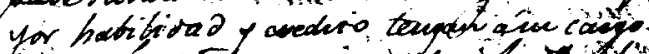

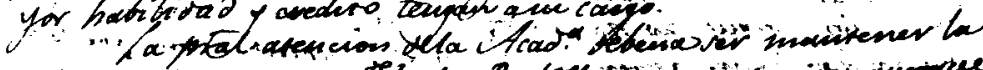

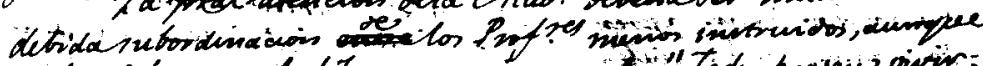

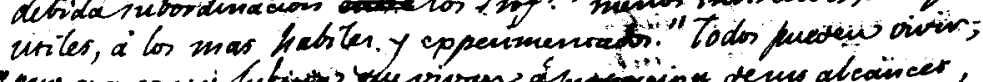

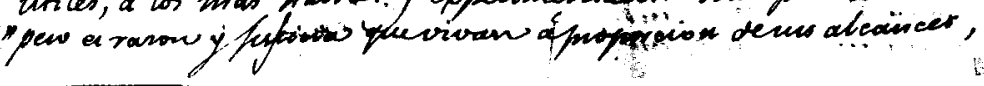

Fig. 7. «Extracto de un papel escrito por el arquitecto D. Juan de Villanueva, en orden a la distinción de Profesores de Arquitectura y el examen de ellos, según sus clases, en la Academia." 1781. A.A.S.F.: Leg.: 17-3/1. fol. 1 anv.-2 rev. 


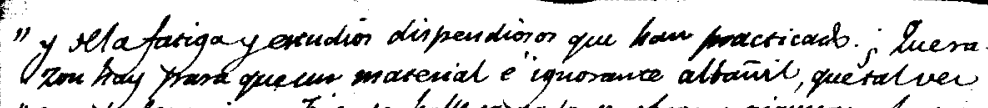

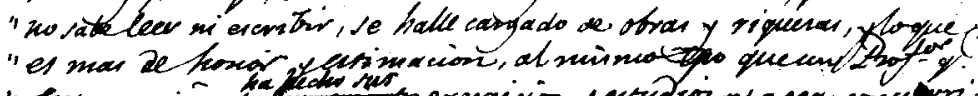

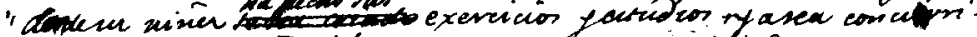

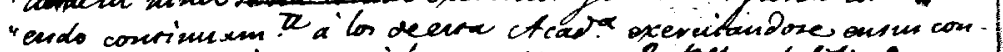

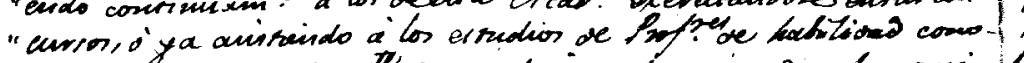

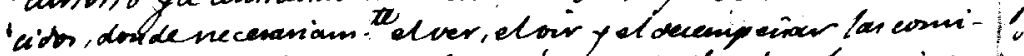

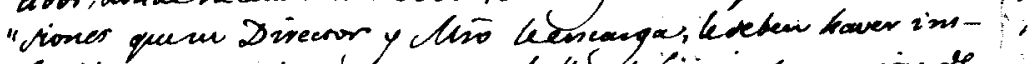

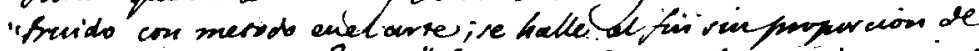

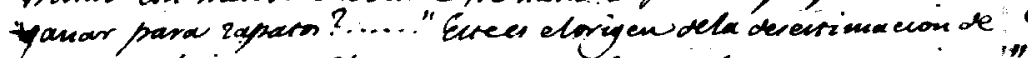

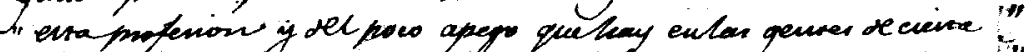

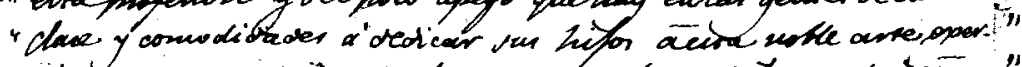

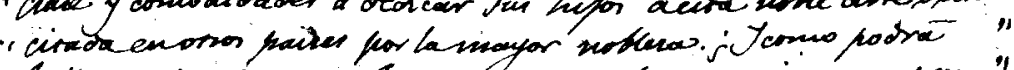

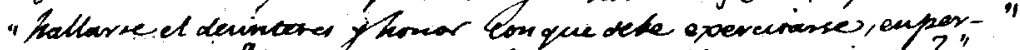

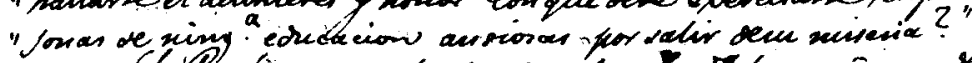

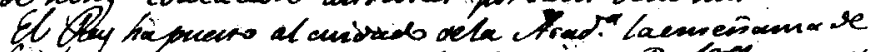

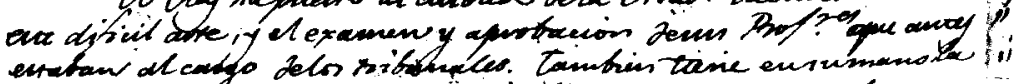

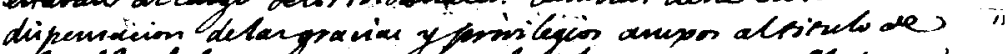

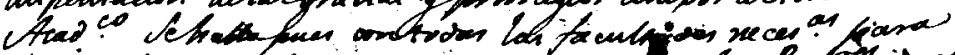

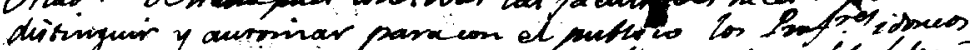

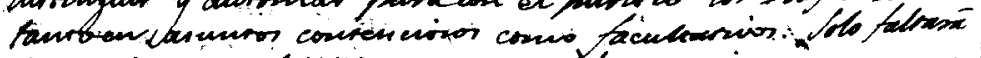

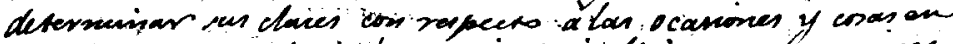

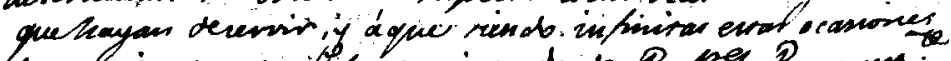

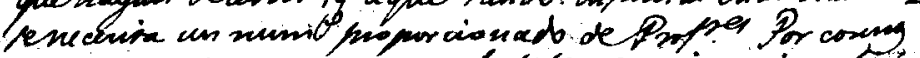

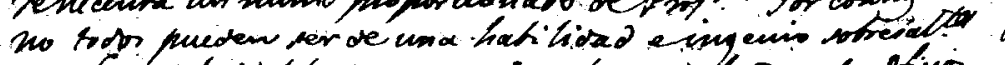

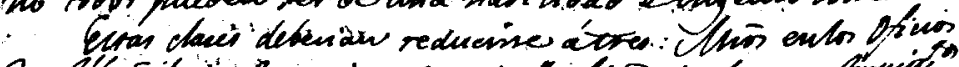

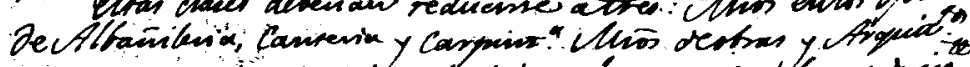

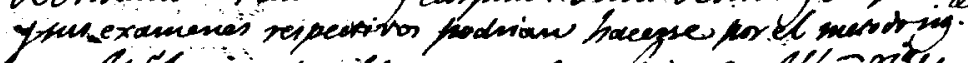

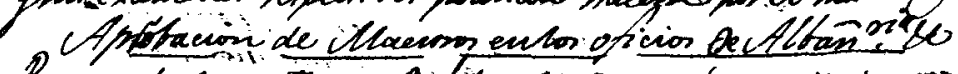

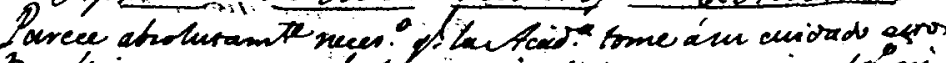

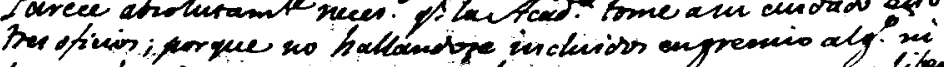

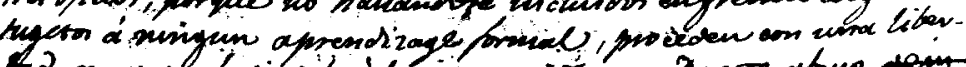

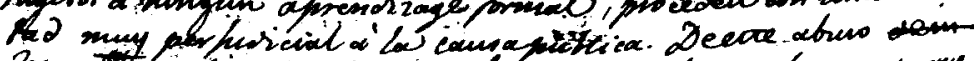

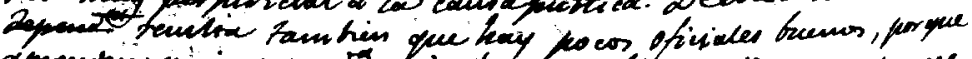

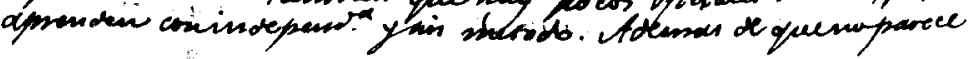

Fig. 8. "Extracto de un. papel escrito por el arquitecto D. Juan de Villanueva, en orden a la distinción de Profesores de Arquitectura y el examen de ellos, según sus clases, en la Academia." 1781. A.A.S.F.: Leg.: 17-3/1, fol. 1 anv.-2 rev. 
El debate académico sobre los exámenes para las distintas profesiones de...

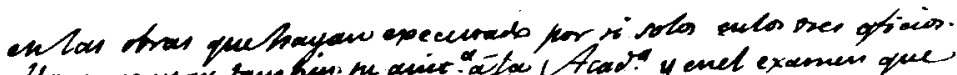

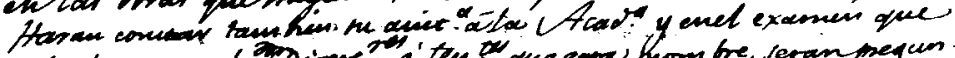

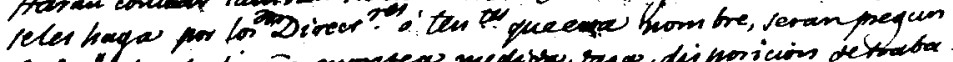

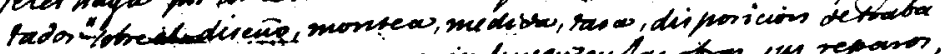

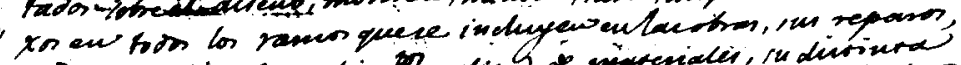

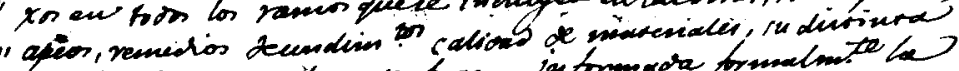

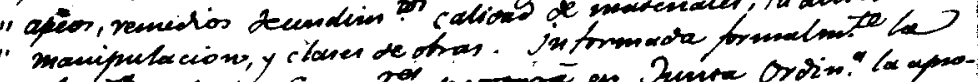

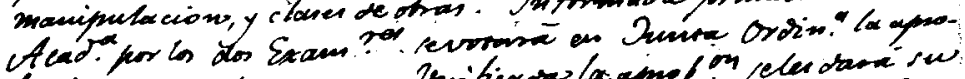

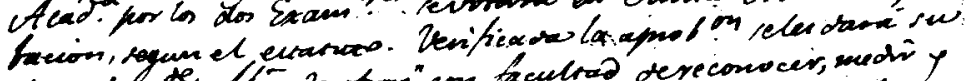

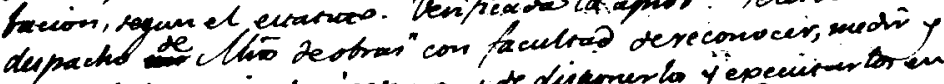

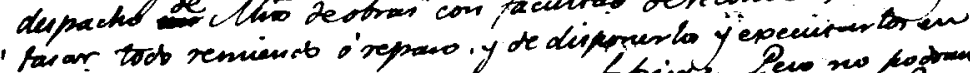

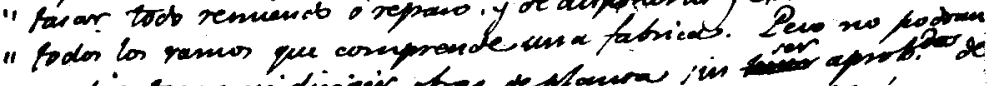

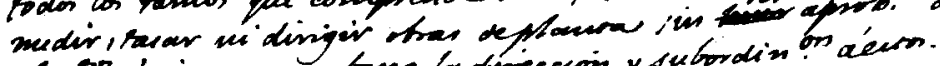

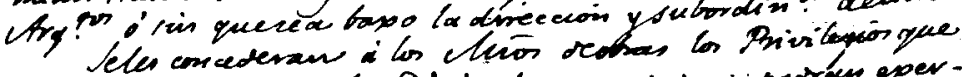

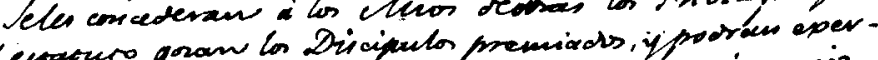

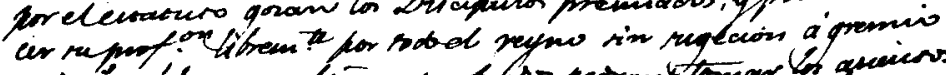

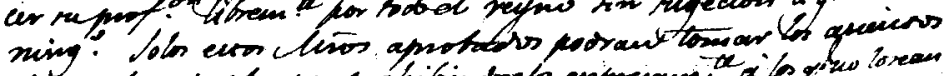

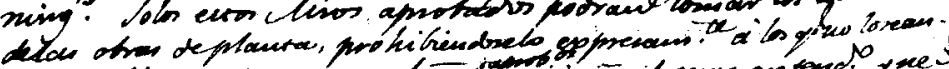

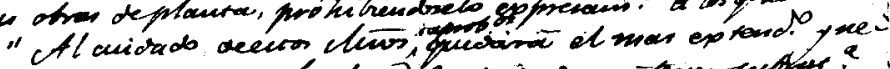

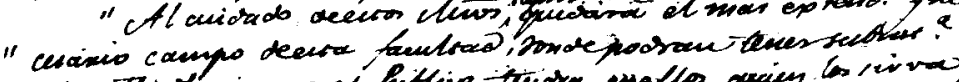

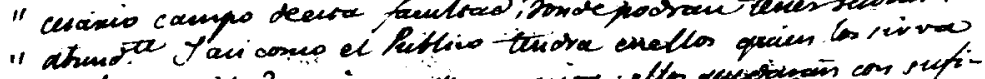

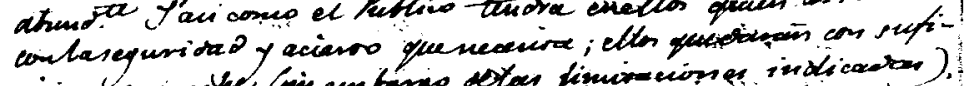

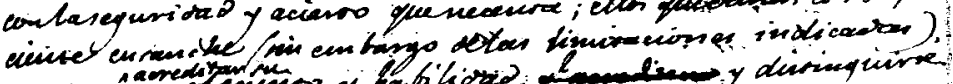

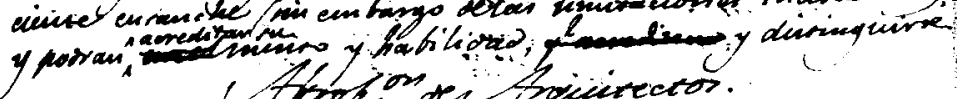

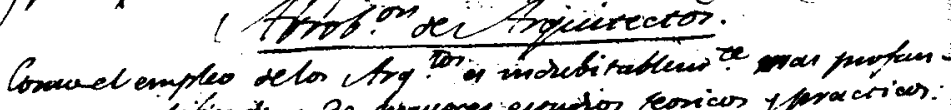

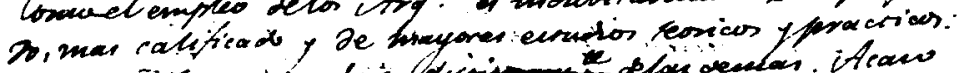

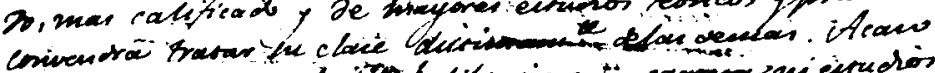

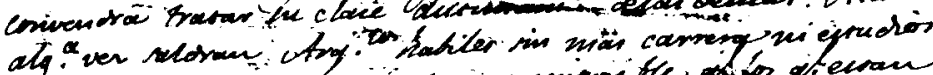

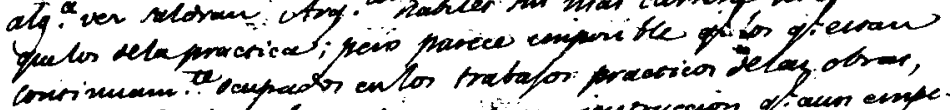

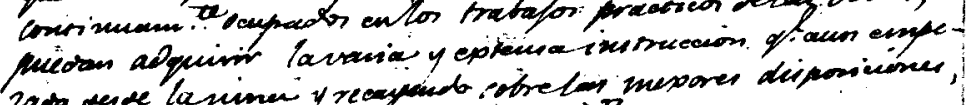

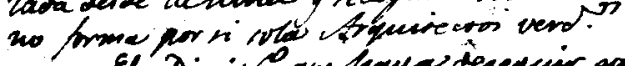

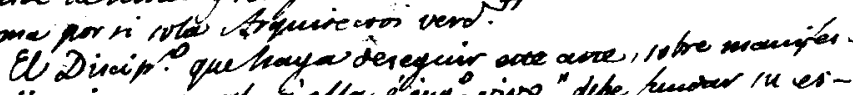

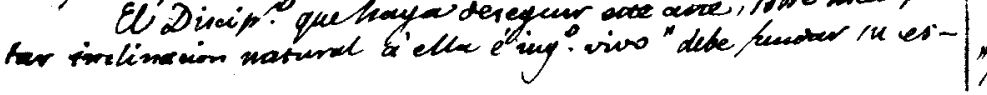

Fig. 9. "Extracto de un papel escrito por el arquitecto D. Juan de Villanueva, en orden a la distinción de Profesores de Arquitectura y el examen de ellos, según sus clases, en la Academia.» 1781. A.A.S.F.: Leg.: 17-3/1, fol. 1 anv.-2 rev. 
quitectura ruina de muchos caudales, y quizá fin de muchas vidas». No obstante, y en contra de la opinión de Silva de las diferencias existentes entre la arquitectura y el resto de las artes, el mismo sistema que se reglamentó para los exámenes a arquitectos en 1783, sería aplicado dos años más tarde a los pintores y escultores por la real orden del 27 de febrero de 1785 firmada por el conde de Floridablanca, quien parecía desear en su gestión política controlarlo todo en la Academia, sin que se le escapase absolutamente nada ${ }^{51}$,

Silva era consciente de la importancia que en la España de la época tenían los maestros de obras, encargados sobre todo de edificar las viviendas comunes. Reflejaba, asi, una idea generalizada en la Academia desde sus mismos orígenes, pues, reconociendo tal interés, había luchado siempre contra los gremios, para que este centro se encargara exclusivamente de la formación de estos profesionales, o, por lo menos, del control de su título y ejercicio. Por este motivo pensaba que, si habían de tener la facultad de inventar y dirigir cualquier fábrica, era preciso que fueran capaces de hacerlo. De esta forma consideraba insuficiente el ligero examen para saber, si podían edificar sin riesgo la casa de un paisano, al cual se les sometía.

En su opinión las reales cédulas de 1777 , por las que se pedía a los intendentes y a los obispos que se presentasen los planos de las obras a la Academia, tenía la finalidad de que los edificios importantes no se confiasen a los maestros de obras. Además, opinaba que Carlos III debió llegar a esta conclusión al estar informado de que las gentes, por lo general, creían que el arquitecto era un simple teórico, por lo cual preferían a aquellos a la hora de construirse edificios. A su juicio el remedio estaba en prescribir límites a las facultades de los maestros de obras.

Pedro de Silva concluía que estos profesionales se deberían examinar para obtener su grado de acuerdo con las edificaciones que hubieren de ejecutar. Era preciso, por lo tanto, examinarles con todo rigor de sus conocimientos sobre cantería, albañilería y carpintería, porque en el caso de carecer de ellos no podrían responder de la firmeza de una casa por pequeña que fuera. Además, y discrepando ahora de nuevo con Villanueva, en el examen no debería intervenir tan sólo un individuo, sino muchos arquitectos.

Se indicará aquí que posteriormente, ya en sus "Reflexiones» de 1792, Silva se manifestó contrario a la existencia de las dos profesiones esta-

51 Real Orden de S. M. de 27 de febrero de 1785, firmada por el conde de Floridablanca, para la recepción de Académicos de mérito en la pintura y escultura. AASF: Leg. 17-3/1. 
blecidas de arquitectos y maestro de obras. Las consideraba equívocas, las identificaba y deseaba, por lo tanto, terminar con la existencia de estos últimos. Sin embargo, quería dar el auge debido a la figura entonces equívoca de aparejador como encargado de ejecutar los proyectos de los arquitectos, de su fábrica. Sus ideas se llevaron en parte a la práctica por medio de la real orden del 18 de septiembre de 1796, que acababa con el título de maestro de obras, otorgado a personas entonces consideradas como simples practicones y faltos de la ciencia suficiente, y se creaba el único de maestro arquitecto con facultades ilimitadas y en posesión de conocimientos conjuntos teóricos y prácticos. No obstante, seguía oficialmente indefinido el empleo de aparejador. Pero, concluida la Guerra de la Independencia, en 1816 se recreó el título de maestro de obras, quizás por la necesidad urgente de reconstruir España, asolada por los combates, y la falta de los suficientes maestros arquitectos para realizarla. Es en este momento cuando se institucionalizó de algún modo la figura del aparejador.

En su parecer de 1782 Pedro de Silva dedicó la mayor extensión a los exámenes de arquitectos, considerados como quienes habrían de tener la facultad de proyectar, dirigir, medir y tasar cualquier fábrica. De aquí que pensara que necesitaban poseer muchos más conocimientos que los maestros de obras. Y volvía a incidir en la incomprensión y falta de estimación del público selecto, de la grandeza, de los magistrados, de los prelados y comunidades eclesiásticas, hacia esta profesión.

Después Silva sintetizó en su escrito las opiniones casi generalizadas de los profesores sobre la forma de realizar los exámenes para obtener el título de arquitecto, quien tendría para ser considerado idóneo que presentarse a todas las partes necesarias de la Arquitectura. Debería comenzar por inventar en planos, alzados y cortes una fábrica con sus diversas circunstancias, a realizar, tal y como se practicaba con las oposiciones a las pensiones en Roma, en el edificio de la Academia. En el primer día se indicaría su pensamiento en un borrador, al cual se debería ajustar después para ejecutar los dibujos en limpio, tomándose para ello el tiempo, que fuera necesario, pero siempre con la condición imprescindible de trabajar en los locales de este centro. A continuación los diseños serían minuciosamente reconocidos por los profesores y se le examinaría sobre aquella misma fábrica para determinar si los había dibujado con conocimiento auténtico o sólo copiando los modelos de otros semejantes conservados en su memoria. Una vez aprobada esta parte, se le examinaría de los conocimientos fundamentales de Cantería, Albañilería y Carpintería, así como de la Geometría y de los cálculos necesarios para desempeñar por completo todas sus facultades. Pero, siguiendo en esta condición los requisitos expuestos por Villanueva, el pretendiente debería 
presentar también un certificado de haber asistido a una fábrica importante bajo la dirección de un arquitecto conocido, pues sin esta experiencia sería simplemente un teórico incapaz de practicar con seguridad.

Terminaba indicando que los maestros de obras deberían sufrir estos mismos examenes para acceder al título de arquitecto. Pero eximía del ejercicio de invención y de delineación a quienes hubieran acreditado en la Academia con oposiciones estar suficientemente instruidos en esta parte, aunque nunca se debería liberar a nadie de los demás ejercicios y de la certificación de haber realizado la práctica.

Por último, Pedro de Silva establecía las condiciones que todo arquitecto aprobado habría de poseer para adquirir la condición de académico. Así, los más sobresalientes habrian de presentar para ser admitidos los dibujos de una de sus obras ya realizada más famosas, siendo juzgada su calidad por la Academia para ser digno de admitirsele. Pero, como no todos los arquitectos tendrían la posibilidad de hacer edificios tan importantes, se les permitiría entregar en su lugar los dibujos de una fábrica ideal. No obstante, eran requisito indispensable ser arquitecto aprobado y también ejercitado. La condición de académico, no se necesitaba, así, para ejercer la arquitectura, sino que era un premio por haberlo hecho con acierto. Por todo lo cual deberían haber pocos y no importaba si éstos fueran buenos.

No obstante, Pedro de Silva cambiaría, o mejor dicho puliría, algunas de estas ideas en sus reflexiones posteriores ya de 1792. Opinó entonces que no había ninguna relación entre el ejercicio público y libre de la arquitectura y su recepción como académico de arquitectura. Así, no se necesitaba ser recibido antes en la Academia para ser considerado como un buen arquitecto. También pensaba que la Academia no tenía la obligación de hacer académicos a todos los que fueran excelentes, sino a aquellos que este organismo considerara como más a propósito a sus fines. Se debería admitirlos por las condiciones particulares poseídas por el individuo, pues algunos por tales razones no convenía que fueran recibidos en el cuerpo de la Academia.

\section{LA REAL ORDEN DEL 24 DE NOVIEMBRE DE 1783}

Los dictámenes de los profesores fueron examinados en la junta ordinaria del 3 de noviembre de 1782. Se decidió en ella que, puesto que los académicos de mérito en arquitectura obtenían según los estatutos las facultades de inventar, dirigir, medir y tasar cualquier edificio público, era preciso que para ello tuvieran todos los conocimientos debidos. Se 
indicaban a continuación los exámenes a los que se les debía someter para conseguir este título.

Antonio Ponz envió al protector Conde de Floridablanca una carta el 15 de enero de 1783 resumiendo lo acordado por la Academia sobre este tema ${ }^{52}$, escrito que motivó la real orden del 24 de noviembre de ese año, que fue recogida en las actas de la junta ordinaria del 7 de diciembre ${ }^{53}$. Esta disposición inspiró, a su vez, la del 27 de febrero de 1785 para la recepción de académicos de mérito en pintura y escultura, en cuyos exámenes se actuaría del mismo modo que lo resuelto para con los de arquitectura ${ }^{54}$.

La real orden del 24 de noviembre de 1783 buscaba la idoneidad de los aspirantes tanto al título de académico de arquitectura como al de maestro de obras. Se les examinaría de dos pruebas diferentes. La primera constaba de dos partes. En el ejercicio inicial el aspirante sería aislado en una sala de la Academia para que, sin ser visto de otros profesores, realizara los dibujos de plantas, cortes y alzados de una fábrica, dándosele para ello el tiempo necesario. Después se le harían preguntas para enterarse si habian sido hechos con «inteligencia radical» y "de propia invención". En la segunda prueba se examinaría al pretendiente a este título del conocimiento fundamental de la construcción en las partes de cantería, carpintería y demás temas correspondientes, así como de geometría y de los cálculos necesarios para el desempeño de su facultad. También se le exigiría un certificado sobre su asistencia a obras de consideración dirigida por arquitecto conocido, para que se supiera que no era un simple teórico.

No obstante, la real orden hacía una serie de puntualizaciones sobre el particular. Así, siguiendo en parte el dictamen de José Moreno, disponía la exención de la primera parte del examen de invención y delineación de una fábrica, a aquellos aspirantes que hubieran acreditado en las oposiciones y concursos de la misma Academia estar suficientemente instruídos, con tal de que con el memorial de su pretensión presentaran los dibujos de alguna obra que hubieran hecho o en su defecto de una fábrica

52 Ponz. Antonio, Borrador de un oficio dirigido al protector Conde de Floridablanca por el secretario de la Real Academia de Bellas Artes de San Fernando sobre la recepción de académicos de arquitectura. Madrid, 15 de enero de 1783. AASF: leg. 17-3/1.

${ }_{53}$ Actas de la junta ordinaria del 7 de diciembre de 1783. AASF: Libro de juntas generales (1774-1785): $3 / 84$, fol. 235 anv.-236 anv.

${ }_{54}$ Real Orden de 27 de febrero de 1785 , firmada por el Conde de Floridablanca sobre la creación de académicos de mérito en pintura y escultura. AASF: 17-3/1. 
ideal. Pero en ningún caso se le eximiría del examen de conocimientos fundamentales ni de presentar ese certificado.

Así, se abría una excepción en la realización de estas pruebas a libre interpretación de la Academia. Estos privilegios darían después lugar a una serie de problemas y desarreglos, pues rompian con la norma. De esta forma el arbitrio de los examinadores a la hora de eximir era un auténtico caballo de Troya, que enredó a este organismo en disputas y reclamaciones.

Estos exámenes, a los que se sometía a los aspirantes a académicos de mérito, se harían extensibles a los pretendientes a maestros de obras. Se deseaba acabar, así, con los perjuicios causados por su impericia, que no era perceptible por medio del ligero ejercicio, que antes se le obligaba a pasar. Se hacía excepción con todos aquellos individuos que sólo aspirasen a dirigir y ejecutar edificios comunes. En este caso tan sólo se requerían sujetos prácticos.

\section{LAS DISPOSICIONES SOBRE LAS DISTINTAS PROFESIONES DE LA ARQUITECTURA (1783-1816)}

El debate académico sobre las profesiones relacionadas con la arquitectura, que promovió la promulgación de la real orden de Carlos III firmada por el conde de Floridablanca en San Lorenzo, del 24 de noviembre de 1783, en un momento de gran interés por ser anterior tan sólo en tres años a la creación de la junta de Comisión de arquitectura, se continuaría posteriormente con otras medidas legislativas importantes. Entre ellas hay que destacar las disposiciones de 1796, que terminaba ocasionalmente con el título de maestro de obras, y 1816, que lo recreaba tal vez por necesidad, al mismo tiempo que se institucionalizaba la profesión de aparejador, hasta entonces indefinida. También es preciso considerar por su gran interés otras disposiciones complementarias y cronológicamente intermedias dictadas por la real resolución del 29 de julio de 1801, estableciendo un reglamento sobre las pruebas a realizar para lograr el título de maestro arquitecto.

Así, en 1796 algunas de las profesiones relacionadas con la arquitectura serían objeto de una destacada reestructuración al suprimirse el grado de maestro de obras y al decidirse, que a partir de entonces tan sólo se expedirían dos títulos diferentes: los de maestro arquitecto y académico de mérito. El primero tenía un carácter de aprobación para el desempeño de este arte, mientras que el segundo lo poseía de incorporación a la 
Academia ${ }^{55}$. Según la propuesta de la junta particular, que deseaba terminar con los abusos introducidos en la práctica de la arquitectura, los profesores directores y tenientes directores de este arte habían escrito una serie de reflexiones sobre las facultades, que competían al título de maestro de obras. Tales escritos fueron estudiados minuciosamente, junto con otros documentos de distintos años conservados en el archivo de la Academia sobre este tema, por dicha junta el 1 de mayo de 1796. Lo acordado se notificó en la ordinaria del 5 de junio, encargándose a Isidoro Bosarte, como secretario de este organismo, que enviara una representación al protector para noticia del rey. El escrito, fechado el día 15 de ese mismo mes, fue aprobado por Carlos IV en San Ildefonso el 18 de septiembre por medio de una real orden firmada por Manuel Godoy, Príncipe de la Paz ${ }^{56}$.

Tal disposición tenía la finalidad de estimular en todo lo posible el estudio de la arquitectura, así como acabar con el título de maestro de obras con facultades restrictivas, que se solía conceder a simples prácticos, faltos de la ciencia suficiente. A partir de este momento se examinaría en conjunto a todo aspirante al título de maestro arquitecto tanto de la práctica como de la teoría, dándosele a este grado unas facultades ilimitadas en el ejercicio de tal arte.

Sin embargo, algunos años más tarde, ya en 1800, se plantearía en la junta ordinaria del 4 de mayo la necesidad de acordar definitivamente los requisitos, que debian recurrir en los maestros arquitectos para promoverles e incorporarles en la Academia con el título de académicos de mérito ${ }^{57}$. El motivo que ocasionó tal revisión fue la real orden del 16 de febrero, en la que se pedia un informe sobre la solicitud enviada por Manuel de la Peña Padura, para que se le elevase a ese grado sin realizar nuevas pruebas ni examen alguno. En dicha junta ordinaria se reconoció la necesidad de resolver este asunto, sobre el que ya se había dialogado algunas veces, desde que la Academia estableció con la aprobación real de 18 de noviembre de 1796 el grado de maestro arquitecto.

Después de largos debates y de votación pública se fijaron en esta junta ordinaria del 4 de mayo de 1800 los requisitos, que deberían tener los maestros arquitectos para ser nombrados académicos de mérito. En primer lugar debía ser "sujeto bien opinado tanto en la parte moral como en la facultativa", imponiéndose, así, la idea expuesta por Ventura Rodríguez

Actas de la junta ordinaria del 5 de junio de 1796 . A.A.S.F.: $3 / 86$, fols. 44 rev. y 45 anv.

Actas de la junta ordinaria del 2 de octubre de 1796 . A.A.S.F.: $3 / 86$, fol. 61 .

Actas de la junta ordinaria del 4 de mayo de 1800 . A.A.S.F.: 3/86, fol. 138. 
en su informe de 1781. Pero antes la junta de la Comisión de Arquitectura había de informar favorablemente las obras presentadas por el aspirante a examen o censura. Además, el pretendiente estaba obligado a escribir un discurso o disertación sobre algún punto del arte, señalado antes por la Academia, dando razón por escrito sobre las preguntas o reparos, que se le hicieran. Una vez aprobado este escrito, su admisión como académico de mérito en el cuerpo de la Academia sería votada de forma secreta.

La representación de este centro de las Bellas Artes se envió el 14 de mayo de 1800 al protector para que, siguiendo el proceso protocolario establecido, la entregara al rey para su conocimiento. Fue aprobada por la real orden fechada el 23 de mayo ese año, dada en Aranjuez y firmada por Mariano Luis de Urquijo. Tal disposición se hizo pública en la junta ordinaria de la Academia del día 1 de junio, al mismo tiempo que el privilegio Real dado por real orden del 26 de mayo de conceder a los individuos y dependientes de la Real Academia de San Fernando los mismos privilegios y prerrogativas, que estaban otorgados y que disfrutaban los de la Real Academia Española en prueba del aprecio, que el monarca hacía del distinguido mérito de ese cuerpo ${ }^{58}$.

Las pruebas a las que se sometía a los aspirantes a graduarse de maestros arquitectos fueron debatidas en la junta ordinaria de la Academia del 3 de mayo de 1801 . Se concluyó entonces la conveniencia de mejorarse. El consiliario Marqués de la Espeja, quien sucedería en 1803 a Bernardo de Iriarte en el empleo de viceprotector, inició el diálogo. Propuso que los pretendientes a este título hicieran constar todas sus circunstancias a la Academia, para que este centro juzgara, si eran dignos para presentarse a examen. Se acordó también que los profesores de Arquitectura se reunieran en una junta extraordinaria para examinar el método vigente de realizar las pruebas, estudiar si era necesario modificarlo e informar con su dictamen sobre el que se debia seguir ${ }^{59}$.

Tal junta extraordinaria se celebraría en la tarde del 28 de mayo de 1801. El secretario Isidoro Bosarte leyó la propuesta acordada para reformar dichas pruebas, que constaba de seis puntos diferentes, en la ordinaria del 7 de junio. La real resolución del 29 de julio de 1801, firmada por Pedro Cevallos, aprobó este reglamento ${ }^{60}$.

Los pretendientes al título de maestro arquitecto debían hacer y entregar en la Secretaría de la Academia los planos de un edificio de su

58 Actas de la junta ordinaria del 1 de junio de 1800 A.A.S.F.: $3 / 86$, fol 139 . rev. y 140 anv.

59 Actas de la junta ordinaria del 3 de mayo de 1801. A.A.S.F.: 3/86, fol. 157.

60 Actas de la junta ordinaria del 7 de junio de 1801 . A.A.S.F.: 3/86, fol. 160 anv. 
invención en pliegos de papel de holanda, que contendrían de forma geométrica los diseños de las plantas, fachadas y cortes. También habrían de dar por separado un informe, en el cual se analizaría el cáculo detallado del costo de la obra, si se hubiera de ejecutar en el sitio pensado por su autor, así como su método de construcción. El secretario los pasaría a continuación a la Junta de Comisión de Arquitectura, para que los profesores examinadores los vieran con toda atención y le remitieran después por escrito su juicio detallado. Aquel debía presentar tales dictámenes en la primera junta ordinaria, tal y como hacía con la censura de los planos de las obras públicas, que llegaban a este centro en cumplimiento de las Reales Ordenes. Inmediatamente después se notificaría al pretendiente a graduarse la opinión que sus trazas había merecido a sus examinadores. El aspirante, en el caso de haber sido aprobado, podría presentar una instancia, cuando quisiera, para hacer la prueba de repente; pero debía obligatoriamente acompañar un certificado de haber realizado prácticas, haciendo constar haber asistido a alguna obra de consideración bajo la dirección de un arquitecto aprobado por la Academia.

Se indicaba también en este reglamento, que, para poder realizar la prueba de repente de una forma adecuada, era preciso antes, que se copiaran de los libros de acuerdos los asuntos dados a quienes se habían examinado de arquitectos desde hacía unos años hasta entonces. Con tales temas se formaría un legajo o libro numerado. Así, una vez que el memorial del aspirante hubiera sido admitido a examen, se sortearía entre ellos el asunto para que hiciera la prueba. El azar señalaría el tema, pues el viceprotector introduciría tres veces seguidas la plegadera en dicho libro, para que el pretendido eligiera uno de entre los tres números registrados. El legajo sería guardado después en una mesa cerrada con llave de la sala de juntas desde el día que se concluyera la ordinaria hasta la siguiente para conseguir la mayor objetividad posible. El conserje le mostraría entonces los temas salidos en suerte y volvería a guardar el libro.

El pretendiente dispondría de una día entero para hacer el examen de repente. Estaría encerrado en una sala desde las siete de la mañana hasta las diez de la noche sin salir para nada del edificio de la Academia. Tendría que dejar asegurado en las pruebas los perfiles y manchados por lo general los esbatimentos o sombras de tinta china en fachada y corte. Siguiéndose el consejo del Marqués de la Espeja se le facilitarían los tratados clásicos de Arquitectura, que necesitara y poseyera la biblioteca de la Academia, que se había abierto al uso de los discípulos en 1794; pero nunca se le entregarían los planos hechos por los profesores ya aprobados para evitar el riesgo de plagio. 
La última parte de las pruebas consistía en un examen oral, que se realizaría el jueves de la misma semana y, si era festivo, el sábado siguiente. En su transcurso los examinadores cotejarían los planos hechos de repente con los realizados de pensamiento, preguntándole sobre cada uno de ellos y acerca de la teoría y práctica de la Arquitectura. La opinión de los profesores se comunicaria al secretario de la Academia para que la hiciera pública en la junta ordinaria siguiente a fin de determinar en ella su aprobación o rechazo.

Fernando VII, a los pocos meses de regresar a España una vez que hubo terminado la Guerra de la Independencia, promulgó una real Cédula, fechada en Madrid el 2 de octubre de 1814, en la que se recordaban las distintas disposiciones dictadas por Carlos III y Carlos IV sobre la profesión de arquitecto, concluyéndose con lo dispuesto en el artículo XXXIII de los Estatutos de la Academia de $1757^{61}$. Se ratificaban en ella la circular del 28 de febrero de 1787, aboliéndose los privilegios conservados por algunos pueblos de otorgar los títulos de arquitectos y de maestros de obras, y la provisión del 5 de enero de 1801, declarándose nulos los títulos expedidos por los Prelados, Cabildos, Ayuntamientos y Gremios.

Las peculiares circunstancias de una España ensangrentada y recién salida de la Guerra de la Independencia contra los franceses, cuyas ciudades habían sufrido los desastres continuos y la destrucción propia de una larga y congruenta contienda, fueron, sin duda, las causas inductoras de la revisión de 1816 de las profesiones de la arquitectura. Fernando VII dirigió el 28 de agosto de este año una real orden a la Academia, promulgada con el dictamen previo de la Comisión de arquitectura, firmada por Pedro Cevallos desde Palacio y dirigida a Martín Fernández de Navarrete, en la cual se estabecían cuatro clases de profesionales relacionados con este arte: académicos de mérito, arquitectos, maestros de obras y aparejadores facultativos. En ella se pedía a la Academia la formación de una ordenanza artística, redactada de una forma clara y sencilla, sobre las facultades competentes a cada una de estas profesiones.

Hay que hacer notar aquí varios hechos muy significativos: En primer lugar la continuidad como grado máximo de incorporación en la vida de la Academia del título de académico de mérito por la arquitectura. Después la desaparición del bastante efímero de maestro arquitecto, una denominación híbrida inventada en 1796 entre las denominaciones de arqui-

61 Sobre esta Real Cédula de 2 de octubre de 1814 puede verse: NAvascués PALACIO, Pedro, "Sobre la titulación y competencias de los arquitectos de Madrid (1775-1825)", en Anales del Instituto de Estudios madrileños, tomo XI, Madrid 1975, págs. 123-137. 
tecto y de maestro de obras, y el retorno de nuevo del simple, pero más exacto, nombre de arquitecto. También se volvía, quizás por la necesidad imperiosa de tener que reconstruir rápidamente un reino devastado, al grado de maestro de obras, una forma fácil de hallar y formar practicones, aunque dándoseles las mismas facultades limitadas tradicionales. Por último, se institucionalizaba, pero siempre con ese matiz ambiguo, la denominación de aparejador al darse a la Academia la facultad de poder premiar alguna vez a determinados sujetos, que por su edad avanzada $u$ otras razones poderosas no hubieran podido alcanzar la clase de maestro de obras. Serían sus virtudes y conocimientos prácticos los factores, que les harían acreedores a tal distinción. 
